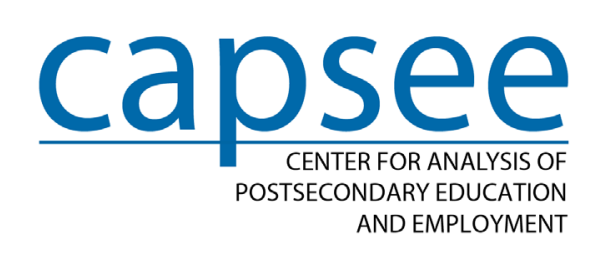

\title{
The Impact of Pell Grant Eligibility on Community College Students' Financial Aid Packages, Labor Supply, and Academic Outcomes
}

\section{A CAPSEE Working Paper}

\author{
Rina Seung Eun Park \\ Community College Research Center \\ Teachers College, Columbia University \\ Judith Scott-Clayton \\ Community College Research Center \\ Teachers College, Columbia University \\ and NBER
}

March 2017

The authors' names are listed alphabetically. R. Park and J. Scott-Clayton contributed equally to this work. The research reported here was supported by the Institute of Education Sciences, U.S. Department of Education, through Grant R305C110011 to Teachers College, Columbia University. The opinions expressed are those of the authors and do not represent views of the Institute or the U.S. Department of Education. The authors are grateful to the staff and administrators at the community college system that facilitated data access and interpretation.

Appendices A, B, C, D, E, and F are available in a separate document available at capseecenter.org.

For information about CAPSEE, visit capseecenter.org. 


\begin{abstract}
In this paper, we examine the effects of receiving a modest Pell Grant on financial aid packages, labor supply while in school, and academic outcomes for community college students. Using administrative data from one state, we compare community college students just above and below the expected family contribution (EFC) cutoff for receiving a Pell Grant. Between 2008 and 2010, students just below the cutoff qualified for an average of \$500 in Pell Grants. We find that other financial aid adjusts in ways that vary by institution: students at schools that offer federal loans borrowed more if they just missed the Pell eligibility threshold, but at other schools, students who just missed the cutoff for Pell were compensated with higher state grants. Focusing on the loan-offering schools where students face a discontinuity in total grant aid, we find suggestive evidence that receiving a modest Pell Grant instead of additional loans leads students to reduce labor supply and increase enrollment intensity. We also provide indirect evidence that students' initial enrollment choices are influenced by an offer of Pell Grants versus loans.
\end{abstract}




\section{Table of Contents}

$\begin{array}{ll}\text { 1. Introduction } & 1\end{array}$

2. Financial Aid at Community Colleges $\quad 4$

3. Data and Sample $\quad 6$

4. Empirical Methodology $\quad 8$

Regression Discontinuity Design $\quad 8$

$\begin{array}{ll}\text { Threats to Validity } & 10\end{array}$

5. Results 12

Effects of Pell Grant Eligibility on Composition of Overall Financial Aid Package 12

Effects of Pell Grant Eligibility on Academic Outcomes and Labor Supply While Enrolled 18

$\begin{array}{ll}\text { Sensitivity Checks } & 20\end{array}$

$\begin{array}{ll}\text { Addressing Sample Selection Bias } & 20\end{array}$

6. Discussion and Conclusion $\quad 29$

$\begin{array}{ll}\text { References } & 31\end{array}$ 



\section{Introduction}

In 1965, President Lyndon Johnson signed into law the Higher Education Act of 1965, which initiated the precursors to today's Pell Grant and Stafford Loan programs and solidified the federal government's role in higher education finance. Since then, the importance of federal financial aid policy has only increased. In 2014-15, the federal government provided over $\$ 120$ billion in student loans, grants, and other forms of financial aid for undergraduates - more than four times the level of support provided in 1990-91.

The federal Pell Grant program is the largest single source of grant aid, providing $\$ 30.3$ billion in grants to over 9 million students annually in $2014-15$, up to $\$ 5,775$ each per year. Students can use the grant at any eligible institution, and receive the same amount regardless of where they go. Although the eligibility formula is complex, family income is the main component: those with family income below $\$ 30,000$ typically receive the maximum award, while only about 5 percent of those with family incomes above $\$ 70,000$ receive any award. If the award exceeds tuition and fees, students can use the extra amount for books, food, or other living expenses.

Although a large body of research convincingly demonstrates that financial aid programs can influence student enrollments and completion (Deming \& Dynarski, 2009; Long, 2008; Page \& Scott-Clayton, 2016), evidence on the effects of Pell Grants specifically is more mixed. Two studies of the effect of the introduction of Pell Grants find no evidence that college enrollments increased any faster for Pell-eligible students relative to ineligible students (Hansen, 1983; Kane, 1995). More recently, a regression-discontinuity analysis of urban community college students just above and below the eligibility cutoff for Pell finds no impact on college choice, course credits or degree completion (Marx \& Turner, 2015). On the other hand, Pell Grants appear to positively influence enrollment rates for adult students (Seftor \& Turner, 2002) and may increase persistence and acceleration in graduation conditional on enrollment (Bettinger, 2004; Denning, 2016).

The ambiguous evidence regarding Pell has led researchers to investigate possible explanations. Several studies have suggested that the complexity of the federal aid application process and late notice of Pell eligibility may undermine the ability of the program to reach students who need aid most (Bettinger, Long, Oreopoulos, \& Sanbonmatsu, 2012; Dynarski \& Scott-Clayton, 2006; Dynarski \& Wiederspan, 2012; Scott-Clayton, 2013).

While progress has been made over the past few years to simplify the federal aid application process and allow students to apply for aid earlier, another potential explanation for the mixed effects of Pell has received comparatively less attention: state and institutional aid policies may interact with the federal aid formula in a way that makes it difficult to isolate the effect of Pell. The interaction of multiple governments' fiscal decisions in a redistributive program like Pell is an example of fiscal vertical externalities (Boadway \& Tremblay, 2012; Johnson, 1988): the federal government acts as the "first mover" by establishing Pell as the 
foundation of financial aid packages (Pell Grants are never reduced as a result of other aid eligibility), but states or institutions as second movers can reduce or retarget their own aid dollars in response.

For example, research by Turner (2014) finds that selective nonprofit institutions capture, via reductions in institutional aid, 67 cents of every Pell dollar received by their students. Bettinger and Williams (2013) also find a negative correlation between Pell Grants and state aid, while McPherson and Schapiro (1991) find a positive correlation between Pell Grants and overall institutional aid. ${ }^{1}$ Finally, studies have found that students may adjust their own borrowing decisions in response to grant eligibility, such that receiving an extra dollar of grant aid often leads to less a dollar of total additional aid received (Goldrick-Rab, Kelchen, Harris, \& Benson, 2016; Marx \& Turner, 2015). Interactions with state and institutional aid programs may also help explain why the estimated effects of Pell are not consistent from study to study, because state and institutional aid programs can vary substantially from context to context.

The availability of large administrative datasets facilitates research designs that were not feasible in decades past. In this paper, we utilize such a dataset from a single state on a population of particular interest: community college enrollees. We implement a regressiondiscontinuity design that examines the effects of just barely qualifying for a Pell Grant on the composition of recipients' overall financial aid package, students' labor supply, and subsequent academic outcomes.

We find that even at community colleges, other sources of student aid do shift substantially around the cutoff for Pell, consistent with Turner (2014) and Marx and Turner (2015). We find distinctive patterns of financial packaging depending on whether or not institutions participated in federal loan programs. At institutions that participated in the federal student loan programs, students above the cutoff (who are ineligible for Pell) borrowed 55 percent more than those below the cutoff. This pattern replicates the findings in previous research by Marx and Turner (2015), though it appears even more strongly in our sample. On the other hand, at institutions that did not offer loans, students just above the Pell cutoff received state/institutional grants that offset the discontinuity in Pell Grants (that is, at schools not participating in the loan programs, there is no discontinuity in overall grant aid around the Pell cutoff).

For our analysis of student labor supply and academic outcomes, we limit the sample to students attending only loan-offering schools, and interpret the estimates as showing the effects of shifting students' aid packages from federal loans to Pell grants. ${ }^{2}$ We find that qualifying for the minimum Pell increases the intensity of enrollment, with recipients 4-7 percentage points

\footnotetext{
${ }^{1}$ Tuition levels are another channel through which the impact of Pell could be diminished (this is often referred to as the "Bennett hypothesis" after former Secretary of Education William Bennett), although empirical research on this question has found mixed results (Rizzo \& Ehrenberg, 2004; Singell \& Stone, 2007; Turner 2014).

2 We distinguish loan-offering schools by looking at average loan take-up rates across cohorts. Although no-loan schools include some with non-zero take-up rates, the rates at those schools were always very close to zero. Loan schools, no-loan schools, and "switchers" were clearly distinguishable.
} 
more likely to enroll full-time from the spring of their first year to the spring of their second year. We also find evidence that those who are just barely eligible for Pell earn less in the first two years after entry, suggesting a reduction of labor supply equivalent to perhaps one or two hours per week. This is consistent with previous findings that grants decrease the need to work for pay and allow students to shift their time allocation from work to school (Benson \& Goldrick-Rab, 2011; Schudde, 2013). For cumulative outcomes at the end of three years - on cumulative GPA, cumulative credits earned, degree completion, and transfer within three years of entry - we cannot detect statistically significant effects, though the point estimates are positive and of a magnitude consistent with the impacts on enrollment intensity throughout the first two years.

After presenting our main results, we examine their sensitivity to possible selection bias. Our analysis uses data on community college entrants, but Pell eligibility may shift who chooses to enroll in a community college in the first place. Indeed, we find a discontinuity in the density of observations around the cutoff that suggests students who qualify for Pell are disproportionately induced not to enroll in community college (perhaps because they attend either a four-year or for-profit institution instead). While we are reassured that student characteristics do not appear to shift around the cutoff, we also address the problem using two methods introduced in the literature: (1) limiting our analysis to a subset of colleges where we do not observe any evidence of differential selection, and (2) performing a bounding analysis under extreme assumptions about the missing population.

Unfortunately, because our main estimates are modest to begin with, they are not particularly robust to these rigorous sensitivity checks, leaving open the possibility that some of the positive effects we find may be due to differential selection into community colleges around the Pell grant cutoff. Still, because we find no differences in observed characteristics around the cutoff, we still view our main results as a reasonable "best guess" regarding the impact of receiving a small Pell grant. In addition, a valuable side effect of examining the potential selection problem is that we can provide some insight on how Pell grant eligibility may influence institutional choice: the selection patterns we find are much more concentrated in areas with many nearby for-profit institutions.

Our paper contributes to the literature in three ways. First, we take a step toward understanding how the nation's largest need-based grant program interacts with other aid programs. We find that other aid programs do respond to the federal Pell Grant. Not only so, we find clear distinctive patterns of financial aid packaging between institutions that participate in federal loans versus those that do not. Second, our paper is one of the few that looks into the interaction of Pell eligibility with employment intensity during enrollment. Much interest in the Pell Grant program has focused particularly on the impacts on college enrollment of low-income students. We show that students who are just below the cutoff (Pell eligible) seem to shift their time allocation, reducing work while increasing their enrollment intensity. Finally, our results provide indirect evidence that Pell Grants may influence student enrollment decisions, in contrast to the findings of Marx and Turner (2015). 
The remainder of the paper proceeds as follows: Section 2 provides background on financial aid at community colleges and on the Pell Grant eligibility formula. Section 3 describes our data and sample. In section 4 , we describe our regression discontinuity strategy and highlight key identification assumptions. Section 5 presents our results, and section 6 discusses implications and open questions.

\section{Financial Aid at Community Colleges}

Among community college students enrolled in 2011-2012, on average, 38 percent of student enrolled received Pell and 17 percent received federal student loans with an average amount of $\$ 1,140$ and $\$ 781$ per enrollee, respectively. ${ }^{3}$ Students qualify for the same amount of Pell regardless of where they enroll, and if the Pell Grant exceeds tuition and fees, students can receive the remainder back as a refund to cover other educational and living expenses.

Pell is by far the largest source of grant aid for community college students, but approximately 12 percent of students also receive state grant aid and 13 percent receive institutional grant aid. While the average amounts of state and institutional aid (approximately $\$ 190$ and \$120, respectively) distributed per enrollee are much smaller than for Pell, our analysis below will suggest that these smaller programs can be particularly important for students around the margin of Pell eligibility. Moreover, institutions may have some discretion about how to distribute state grant aid. In the state we examine here, the state's need-based grant is given as a lump sum to institutions, which can then use their own formula to provide aid to students, as long as it is need-based.

To qualify for any federal aid, students must file a Free Application for Federal Student Aid (FAFSA). This application collects detailed information on students' income and assets, as well as similar information from the parents of dependent students. This information is used in a complex formula that provides an "Expected Family Contribution" or EFC as its output. While over a hundred pieces of information are required to precisely calculate the EFC, for the vast majority of students, the EFC is determined by income, family size, and number in college (Dynarski, Scott-Clayton, \& Wiederspan, 2013). Lower income students will have lower EFCs. The EFC is used to distribute not just federal aid, but frequently state and institutional aid as well.

Pell eligibility is directly related to EFC: in general, Pell eligibility equals the maximum Pell in a given year, minus EFC. However, in most years, there is a minimum grant size such that the Pell does not decline continuously to zero, but may drop from several hundred dollars to zero at a certain point in the EFC distribution. The precise formula varies from year to year. In many years prior to 2008 , the minimum grant size was $\$ 400$ (those with eligibility between $\$ 200$ and $\$ 399$ were rounded up, while those with eligibility below $\$ 200$ received nothing). In years since

\footnotetext{
${ }^{3}$ Authors' tabulations using NCES QuickStats with NPSAS:2012 data split by institution type.
} 
2011, the minimum grant has been $\$ 200$. However, between 2008 and 2010, the minimum grant size was much larger than usual, in part due to additional American Reinvestment and Recovery Act funding. In 2008-09 the minimum was $\$ 690$, rising to $\$ 976$ in $2009-10$, and falling back to $\$ 555$ in 2010-11. We thus focus on these years for our regression discontinuity analysis.

Eligibility for subsidized student loans is calculated as the total cost of attendance (including estimated living expenses for students attending at least half-time), minus the EFC and other aid already received by the student, subject to annual loan maximums. Students are eligible for unsubsidized loans regardless of EFC. Between 2008 and 2010, the combined limit of subsidized and unsubsidized loans for first-year students was around $\$ 5,500$ annually for dependent students and $\$ 9,500$ annually for independent students. ${ }^{4}$ It is also worth pointing out that total costs of attendance are high enough even at community colleges such that students receiving the minimum Pell Grant are very unlikely to have their state financial aid limited by the cost of attendance (in 2008, for example, average total cost of attendance for full-time students at community colleges was $\$ 9,700){ }^{5}$

Not all students at community college receive a federal loan offer in their financial aid packages. Colleges sometimes choose to opt out of the Stafford loan program in fear of sanctions by the federal government. ${ }^{6}$ For students who are eligible for the Pell Grant, those attending colleges that include a federal loan offer in their financial aid package have a higher likelihood and amount of borrowing as well as a higher number of attempted credit hours in the first year, relative to students attending colleges that do not include loans in their aid packages (Wiederspan, 2016).

Examining the effect of a modest Pell Grant for students at community colleges has two advantages. First, the monetary incentive is sharpest for these students: the minimum Pell Grant, which averaged $\$ 750$ between 2008 and 2010, represented a more than 25 percent discount on tuition and fees during that time period. ${ }^{7}$ Second, because of open-access admissions, community college enrollees are arguably more likely to be on the margin of college attendance and persistence (i.e., potentially more likely to change behavior as a result of aid), and thus represent a key target population for need-based aid.

\footnotetext{
${ }^{4}$ Federal loan limits are resourced from http://www.finaid.org/loans/historicallimits.phtml

${ }^{5} 2008$ figure based on NPSAS:2008 data, using "student budget (attendance adjusted)" variable for full-time students.

${ }^{6}$ If an institution has more than a 30 percent cohort default rate for three consecutive years, that school is prohibited to offer any federal financial aid, including Pell Grant, for three years (Wiederspan, 2016).

${ }^{7}$ Based on estimated average tuition and fees of \$2,713 in 2010-11 (Baum \& Ma, 2011).
} 


\section{Data and Sample}

The administrative data we use include information from more than 20 community colleges in a single state. The data include five types of information: student demographics, firstyear financial aid eligibility and receipt, transcript data, degree/transfer information, and quarterly earnings. Student demographics include race/ethnicity, gender, age, family income, and dependency status. Financial aid information includes the expected family contribution or EFC (the summary measure of financial need which determines eligibility for Pell and other federal aid), and amounts of federal, state, and institutional aid actually received (broken out into detailed types of aid). Transcript data include remedial placement test scores for those who took such tests, credits attempted and earned, and grades for each term enrolled in any of the states' community colleges. Credential completion and transfer to four-year institutions are measured using data from the National Student Clearinghouse (NSC), which include data for students who leave the community college system. Finally, student records are matched to quarterly earnings records, which we use to measure of student labor supply during the first two years post-entry.

The data are limited to first-time, fall entrants to the community college system. We focus on the 2008-2010 entry cohorts because of particularly large discontinuities in the Pell formula during those years (in earlier and later years, minimum awards were much smaller). In these years, the data include a total of 89,000 students. We further limit our sample to the 57 percent of students who filed a FAFSA (and thus have the financial information we need for the regression discontinuity analysis) and have EFCs within \$2,000 of the Pell cutoff in the relevant year.

Table 1 shows the characteristics and financial aid measures of our sample. The first three columns describe our analysis sample, while the fourth column provides statistics on the full sample of enrollees (regardless of EFC and including those who did not file a FAFSA) during these years, for comparison. ${ }^{8}$ The majority of students in our sample are White students, about equally distributed in gender. On average, students in entry cohorts are slightly above 21 years old. About 60 percent of students in our analysis sample persisted to the subsequent fall, and about one-third transferred or received a degree within three years of entry. The final column provides national averages from the Beginning Postsecondary Students (BPS) 2012/2014 survey, representing first-time students who entered a public two-year college during academic year 2011-12. On average, compared to the BPS sample, our main analysis sample (column 3) has fewer Hispanic students, and has lower family income. In terms of financial aid, students in our sample received less state aid and borrowed less compared to the BPS sample.

Table 1 indicates that students above and below the EFC cutoff for receiving Pell are actually quite similar along most demographic dimensions other than family income. This confirms large differences in Pell receipt around the cutoff, but also highlights that students who

\footnotetext{
${ }^{8}$ For dependent status, family income, family size, and EFC, our data has information only on those who have filed a FAFSA.
} 
are ineligible for Pell are also much more likely to take out student loans, and somewhat more likely to receive state grant aid. We will examine these patterns in more detail below.

Table 1: Sample Characteristics of 2008-2010 Cohort by Pell Grant Eligibility

\begin{tabular}{|c|c|c|c|c|c|}
\hline \multirow[b]{2}{*}{ Variable } & \multicolumn{3}{|c|}{ Mean ( \pm 2000 bandwidth) } & & \\
\hline & \multicolumn{5}{|c|}{ (1) Pell Eligible (2) Pell Ineligible (3) Combined Sample (4) Full Sample (5) National Avg. } \\
\hline Female & $54 \%$ & $55 \%$ & $55 \%$ & $53 \%$ & $53 \%$ \\
\hline \multicolumn{6}{|l|}{ Race } \\
\hline Black & $25 \%$ & $23 \%$ & $24 \%$ & $24 \%$ & $13.4 \%$ \\
\hline Hispanic & $7.0 \%$ & $6.8 \%$ & $6.9 \%$ & $7.0 \%$ & $23.9 \%$ \\
\hline Asian & $4.6 \%$ & $5.2 \%$ & $4.9 \%$ & $6.0 \%$ & $4.8 \%$ \\
\hline White & $62.7 \%$ & $64.5 \%$ & $63.5 \%$ & $61.8 \%$ & $53.1 \%$ \\
\hline Amer-Indian & $0.6 \%$ & $0.4 \%$ & $0.5 \%$ & $0.5 \%$ & $0.8 \%$ \\
\hline Age (years) & 21.4 & 21.1 & 21.2 & 21.7 & 21.5 \\
\hline Any dual enrollment & $24 \%$ & $23 \%$ & $24 \%$ & $17 \%$ & NA \\
\hline Persisted to Spring Term & $83 \%$ & $83 \%$ & $83 \%$ & $76 \%$ & NA \\
\hline Persisted to Next Fall & $61 \%$ & $63 \%$ & $61 \%$ & $56 \%$ & NA \\
\hline Trans/Deg w/ in 3 Years & $31 \%$ & $34 \%$ & $32 \%$ & $28 \%$ & NA \\
\hline \multicolumn{6}{|l|}{ Pre-test scores } \\
\hline Reading & 53.7 & 55.3 & 54.4 & 51.9 & NA \\
\hline Writing & 47.3 & 49.0 & 48.0 & 44.9 & NA \\
\hline Math & 19.1 & 20.5 & 19.7 & 18.5 & NA \\
\hline \multicolumn{6}{|l|}{ Prior Earnings } \\
\hline 1 year prior & $\$ 2,760$ & $\$ 3,109$ & $\$ 2,911$ & $\$ 2,740$ & NA \\
\hline 2 year prior & $\$ 1,601$ & $\$ 1,675$ & $\$ 1,633$ & $\$ 1,444$ & NA \\
\hline \multicolumn{6}{|l|}{ Financial Aid } \\
\hline Applied for financial Aid & $100 \%$ & $100 \%$ & $100 \%$ & $57 \%$ & NA \\
\hline Dependent & $80 \%$ & $81 \%$ & $80 \%$ & $69 \%$ & $71 \%$ \\
\hline Family Income & $\$ 45,454$ & $\$ 55,891$ & $\$ 49,961$ & $\$ 39,768$ & $\$ 59,365$ \\
\hline Family Size & 3.4 & 3.5 & 3.4 & 3.3 & NA \\
\hline $\mathrm{EFC}$ & $\$ 3,495$ & $\$ 5,523$ & $\$ 4,371$ & $\$ 4,545$ & $\$ 6,494$ \\
\hline Received Pell Grant & $94 \%$ & $0 \%$ & $53 \%$ & $41 \%$ & NA \\
\hline Average Pell (Incl. 0s) & $\$ 1,261$ & $\$ 1$ & $\$ 717$ & $\$ 1,368$ & $\$ 1,501$ \\
\hline Received Total Grant & $96 \%$ & $65 \%$ & $83 \%$ & $49 \%$ & NA \\
\hline Average total grant (incl. 0s) & $\$ 2,164$ & $\$ 1,065$ & $\$ 1,689$ & $\$ 1,705$ & $\$ 2,287$ \\
\hline Received State aid & $53 \%$ & $59 \%$ & $55 \%$ & $2097 \%$ & NA \\
\hline Average State aid (incl. 0s) & $\$ 618$ & $\$ 735$ & $\$ 669$ & $\$ 188$ & $\$ 293$ \\
\hline Any fed loan & $22 \%$ & $39 \%$ & $29 \%$ & $1226 \%$ & NA \\
\hline average loan amt (incl. 0s) & 819 & 1442 & 1088 & 507 & 832 \\
\hline Sample Size & 4,463 & 3,392 & 7,855 & 89,205 & 9,587 \\
\hline
\end{tabular}

Note. Columns 1-3 are restricted to samples of 2008-2010 fall entry cohort students who have filed FAFSA, for whom race/ethnicity is not missing, and who fall within $+/-\$ 2,000$ of the EFC cutoff for receiving Pell. Column 4 is for the entire 2008-2010 cohort, regardless of EFC or whether a FAFSA was filed (except for dependency, income, family size, and EFC, which are only available for FAFSA applicants). Column 5 shows averages for the nationally representative BPS 2012/14 sample, restricted to those who entered a public two-year college for the first time in academic year 2011-12. 


\section{Empirical Methodology}

\section{Regression Discontinuity Design}

We use a Regression Discontinuity (RD) design to estimate the causal effect of Pell Grant eligibility for those near the EFC cutoff, using EFC as our forcing variable. The statutory discontinuity in Pell for a full-time student was $\$ 690$ in 2008-09, \$976 in 2009-10, and $\$ 555$ in 2010-11 (awards are prorated for less-than-full-time enrollment). ${ }^{9}$ The formula is reflected in Figure 1, which plots students' estimated Pell eligibility based on their EFC. We use estimated Pell eligibility here instead of actual Pell amounts received, because amounts received are endogenous to enrollment intensity. Later graphs that show actual Pell received will reflect a similar, if slightly muted pattern (since amounts received can only be equal to or less than estimated eligibility).

\section{Figure 1: Estimated Pell Grant by EFC (2008-10 Cohort)}

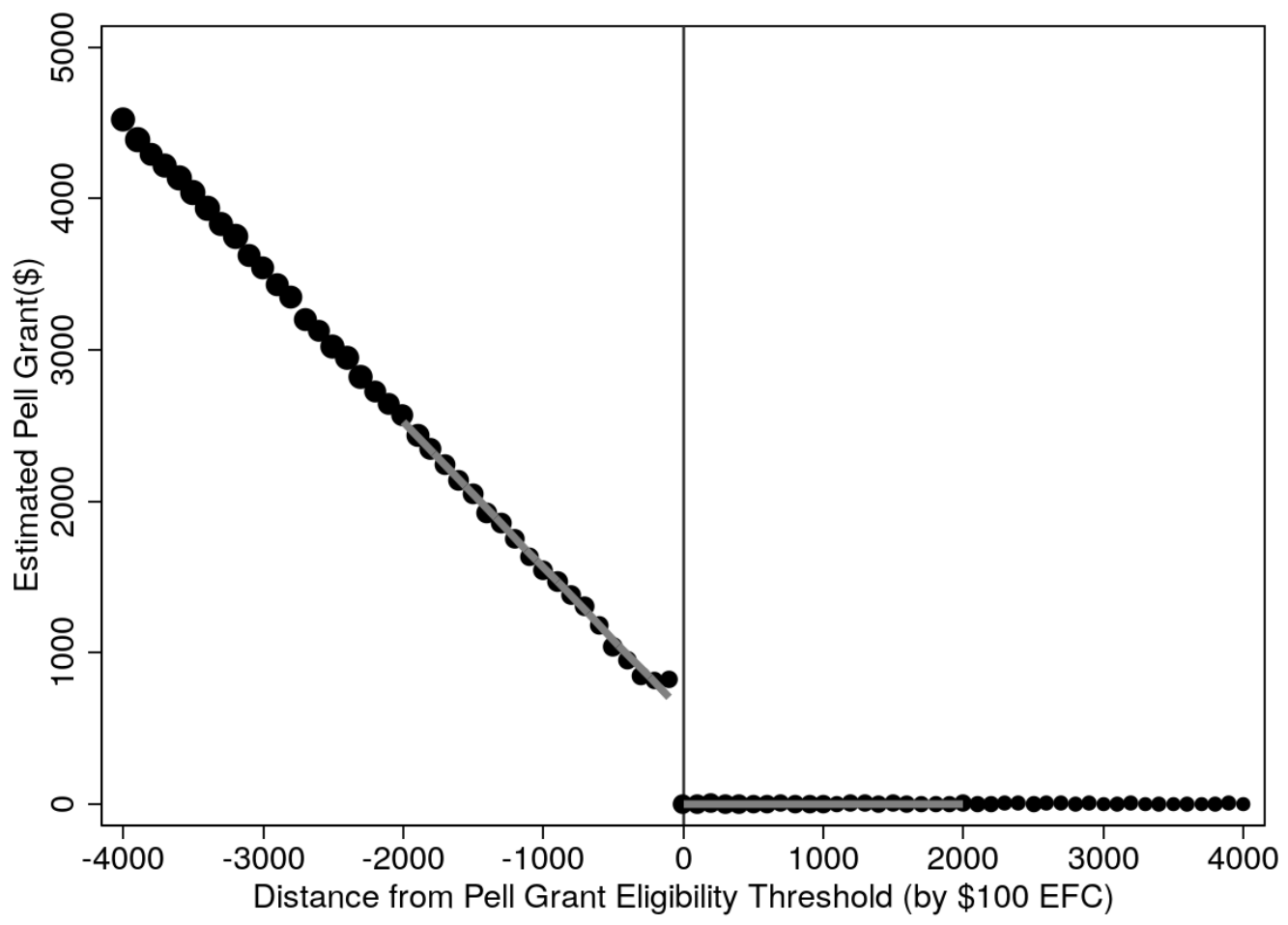

Note. Samples are restricted to 2008-2010 cohort students who have filed FAFSA, for whom race/ethnicity is not missing, and who are non-dual enrollees. Estimated Pell amount is computed by EFC assuming full-time enrollment intensity. Each point is a mean value of the outcome that falls within a bin of size \$100 EFC. Graph shows only points that fall within the $+/-\$ 4,000$ bandwidth. Gray line is a fitted line of mean points within a $+/-\$ 2,000$ bandwidth.

\footnotetext{
${ }^{9}$ In 2008 and 2009, Pell simply rises linearly below the cutoff until it reaches the maximum. In 2010, the formula takes a particularly weird shape, with eligibility fixed at $\$ 555$ for students within a range below the threshold, then rising linearly for a range, then discontinuously jumping again by about $\$ 327$ at an EFC approximately $\$ 500$ below the cutoff. This odd pattern in 2010 can be detected in Figure 1.
} 
The intuition behind the $\mathrm{RD}$ is that if we can assume that the relationship between EFC and an outcome variable is continuous as we approach the cutoff from either direction, then any discontinuity in the outcome at the cutoff can be attributed to the discontinuity in treatment. Formally, using Rubin's (1974) potential outcomes framework, let $Y_{0 i}, Y_{1 i}$ be potential outcomes for an individual $i$ without treatment and with treatment, respectively. Let PellEligible $e_{i} \in\{0,1\}$ indicate treatment status. We can then model outcomes as:

$$
Y_{i}=Y_{0 i}+\left(Y_{1 i}-Y_{0 i}\right) \text { PellEligible }_{i}=f\left(E F C_{i}\right)+\beta_{i} \text { PellEligible }_{i}+v_{i}
$$

where, $\beta_{i}$ is the treatment effect, $E\left[Y_{0 i} \mid E F C_{i}\right]=f\left(E F C_{i}\right)$, and $v_{i}=Y_{0 i}-E\left[Y_{0 i} \mid E F C_{i}\right]$. The idea behind the RD design is that Pell eligibility is fully determined by EFC (i.e., PellEligible $=$ $g(E F C))$.

Causal inference in the RD model relies on two assumptions: (1) a discontinuity in treatment assignment $E\left[\right.$ PellEligible $\left.{ }_{i} \mid E F C_{i}=c\right]$ exists at the cutoff $\left(c_{0}\right)$ and (2) $\left(E F C_{i}\right)$ is continuous in the neighborhood of the cutoff $\left(c_{0}\right)$ (Hahn, Todd, \& Van der Klaauw, 2001; Imbens \& Lemieux, 2008). If all assumptions above hold, then the local average treatment effect is:

$$
\beta=\lim _{c \rightarrow c_{0^{+}}} E\left[Y_{i} \mid E F C_{i}=c\right]-\lim _{c \rightarrow c_{0^{-}}} E\left[Y_{i} \mid E F C_{i}=c\right]
$$

In words, the RD estimate is the difference of two regression functions at the cutoff $\left(c_{0}\right)$. We use a "sharp" RD estimator, since the treatment of interest is Pell eligibility rather than receipt, and eligibility is completely determined by the forcing variable. Refer to Appendix D for the relationship between EFC and the actual probability and amount of Pell receipt.

We implement the RD using a local linear regression estimator with a rectangular kernel (i.e., with all observations weighted equally) for observations within $+/-\$ 2,000$ from the EFC cutoff (Hahn et al., 2001; Imbens \& Lemieux, 2008) ${ }^{10}$ Specifically, we estimate:

$$
Y_{i s t}=\alpha+\beta_{1}\left(\text { PellEligible }_{i t}\right)+\beta_{2}\left(\text { Dis }_{i t}^{*} \text { Above }_{i t}\right)+\beta_{3}\left(\text { Dis }_{i t} * \text { Below }_{i t}\right)+X_{i} \delta+\phi_{s}+\tau_{t}+\varepsilon_{i s t}
$$

where, Dis $\mathrm{t}_{i t}$ is distance from the EFC cutoff for Pell eligibility in year $\mathrm{t}\left(\right.$ Dist $_{i t}=E F C_{i t}-$ $\left.c_{0 t}\right)$, Above $_{i t} /$ Below $_{i t}$ is a binary outcome indicating whether individual $i$ in year $t$ has EFC that is above or below the cutoff; $X_{i}$ is a vector of individual-level covariates including race/ethnicity dummies, age, income, dependent status, whether the student had dual enrollment credits from high school, and placement math, reading, and writing scores (with flags for missing scores); $\phi_{s}$ is a vector of school fixed effects; and $\tau_{t}$ is vector of dummies for each cohort. If the

\footnotetext{
${ }^{10}$ When using a subset of points to fit a local regression, different weights can be used to the fit data points (mostly, weight is given as a function of distance to the point estimator). This weight function is referred to as a kernel. In the regression discontinuity literature, there is no consensus in an optimal choice of kernel because in practice different weight functions should have little impact on the estimator (DesJardins \& McCall, 2008; Fan \& Gijbels, 1996; Lee \& Lemieux, 2010; McCrary \& Royer, 2003). For consistency, we use a rectangular kernel, giving equal weights to all local points within the bandwidth, throughout the paper as suggested by Lee and Lemieux (2010).
} 
RD assumptions hold, adding covariates $\left(X_{i}\right)$ is not necessary for identification of causal effects, but will adjust for small sample bias and reduce standard errors.

In addition to testing for sensitivity across different bandwidths, we also use three bandwidth selection methods: cross validation (Ludwig \& Miller, 2005) and two plug-in rulesImbens and Kalyanaraman (2012) (hereafter, IK) and Calonico, Cattaneo, and Titiunik (2014) (hereafter, CCT) — as a comparison to our baseline specification. ${ }^{11}$ We estimate optimal bandwidths under each method for all the outcomes separately and examine their distribution.

\section{Threats to Validity}

A key assumption for an unbiased RD estimator is that individuals should not be able to systematically manipulate whether they fall above or below the cutoff of the forcing variable. Because of the opaque nature of the EFC calculation, the fact that both the EFC formula and the relevant cutoffs change from year to year, and the fact that a high proportion of financial aid applicants will have to submit tax documents to verify their income, we are skeptical that students/families can manipulate their EFCs very precisely.

However, another way that the assumption of continuity in $f\left(E F C_{i}\right)$ can be violated is if there is differential sample selection around the cutoff. This is a bigger concern in this context, because our sample includes only students who ultimately enrolled in the community college system, and most students learn their aid eligibility prior to initial enrollment. If Pell eligibility induces some individuals to enroll in college who would not have otherwise, or if it influences students' choice of institution, this will cause a discontinuity in $f\left(E F C_{i}\right)$ within our sample frame.

This assumption can be tested by examining the density of observations around the cutoff. As shown in Figure 2, which plots density using $\$ 100$ EFC bins, we can see that there is a jump in the number of observations just to the right of the cutoff; that is, students are more likely to appear in our community colleges sample if they are ineligible for Pell. The direction of this enrollment jump is counterintuitive to what we would expect if Pell Grant induced student's enrollment choices. To confirm this discontinuity, we conduct a McCrary (2008) test, which rejects the null hypothesis that the density is smooth. Given the direction of enrollment jump, we hypothesize that the "missing" students to the left of the cutoff may be using their Pell Grants to attend schools other than community colleges. We explore this hypothesis further in the section following our main results.

\footnotetext{
${ }^{11}$ Lee and Lemieux (2010) also use the rule-of-thumb bandwidth procedure introduced by DesJardins and McCall (2008). We also run the rule-of-thumb procedure and find it suggests similar, but slightly smaller bandwidths than the IK procedure.
} 


\section{Figure 2: Density Plot for All Schools}

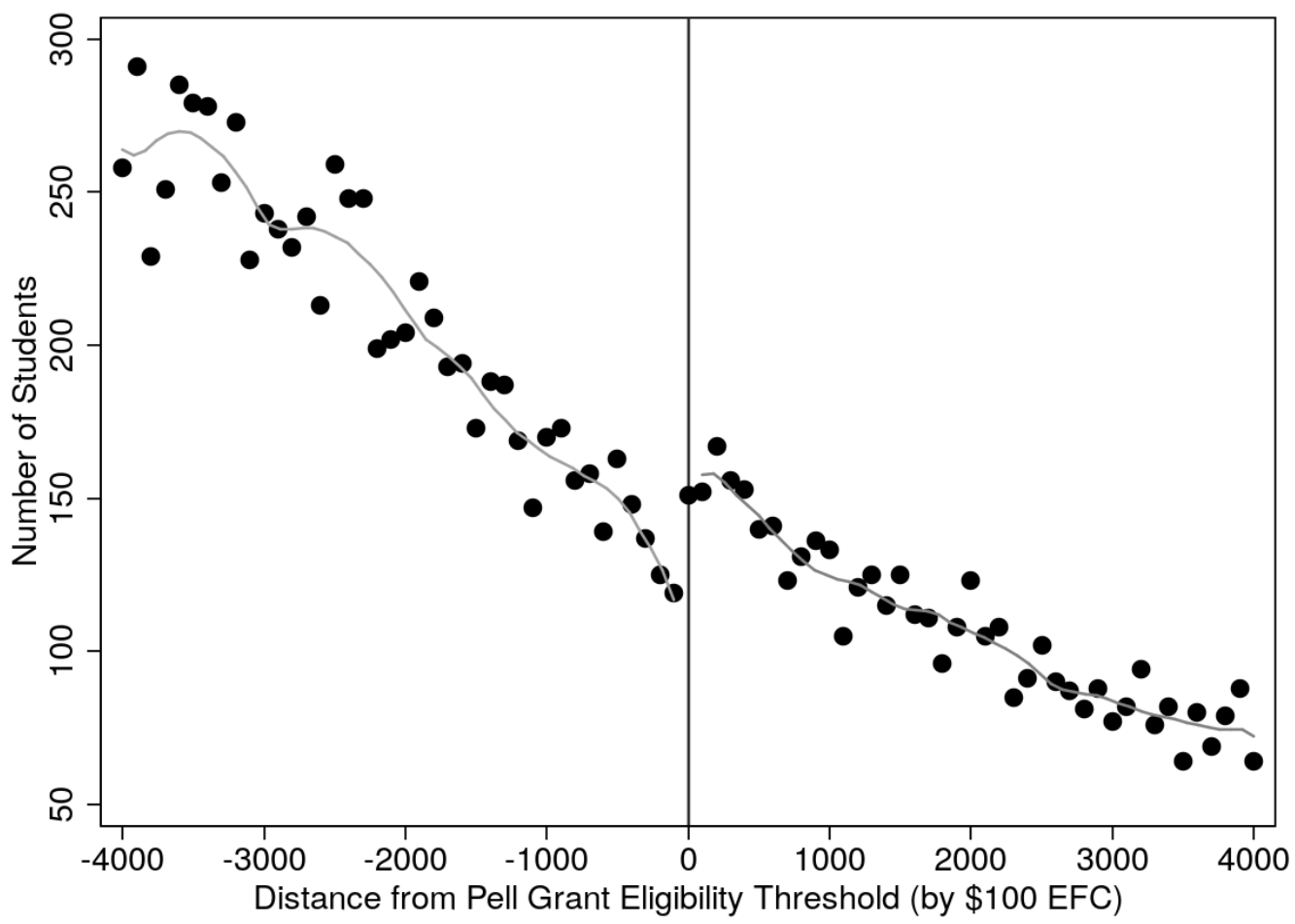

Note. Samples are restricted to 2008-2010 cohort students who have filed FAFSA, for whom race/ethnicity is not missing, and who are non-dual enrollees. Points represent number of students (sum count) that fall within a bin of size $\$ 100$ EFC. Points within a $+/-\$ 4,000$ bandwidth are included in the figure. Gray line is a local smoothed polynomial line with degree 2 , using points within the $+/-\$ 4,000$ bandwidth.

Another approach to evaluating selection bias around the cutoff is to test for discontinuities in the baseline covariates around the EFC cutoff. Appendix Table $\mathrm{C} 1$ illustrates the relationship between covariates and EFC where we use a version of equation (3) above with covariates on the left-hand side to test for any significant discontinuities. Reassuringly, despite the substantial discontinuity in the density, we find no evidence of discontinuities in any baseline covariates at the cutoff in our preferred $\$ 2,000$ bandwidth, including not just age, race/ethnicity, and gender, but also family income, dependency status, and placement test scores. ${ }^{12}$ This conclusion holds even after limiting the sample to loan schools (see Appendix Table $\mathrm{C} 1$ and Appendix E), which have the largest discontinuity in density.

Our primary strategy to mitigate selection bias is to control for observable characteristics around the cutoff. In addition, to assess the possible role of selection on unobservable dimensions, we test the sensitivity of our results by following two procedures introduced in the literature: (1) analysis of impacts for a subset of institutions for which no discontinuity in the density of observations is observed (as proposed by Calcagno \& Long, 2008), and (2) an RD

\footnotetext{
${ }^{12}$ For the $\$ 4.000$ bandwidth specification, we see dual enrollment, age, and dependent variables as significantly different.
} 
bounding analysis (as proposed by Gerard, Rokkanen, \& Rothe, 2016 [hereafter, GRR]). We describe these strategies in more detail after presenting our main results.

Finally, it is worth noting that while this discontinuity is problematic for an analysis of outcomes among community college enrollees, it also provides indirect evidence that Pell eligibility does influence initial enrollment decisions, which is an important margin of impact on its own. This is in contrast to findings in Marx and Turner (2014), who find no evidence that Pell eligibility affects either the enrollment margin or the choice of two- versus four-year college for students who applied to CUNY colleges. ${ }^{13}$

\section{Results}

\section{Effects of Pell Grant Eligibility on Composition of Overall Financial Aid Package}

The two panels of Figure 3 illustrate how different components of students' aid packages change around the Pell eligibility cutoff, with observations grouped into \$100 EFC bins and the size of each circle reflecting the number of observations. All panels plot data for students at loan schools and no-loan schools separately, for reasons that will become clear. The left panel shows actual Pell Grant amounts received, and indicates an increase of approximately $\$ 500$ just to the left of the cutoff, with no difference between loan and no-loan schools. ${ }^{14}$ However, a clear difference between these two institution types emerges when we look at the right panel, plotting average total grants by EFC. Across most of the EFC distribution, the institutions that do not offer student loans give out more in total grants. They also use state grant aid to compensate students just above the cutoff for Pell, such that at these institutions, there is no discontinuity in total grant aid around the Pell cutoff. A large discontinuity in total grant aid exists only for institutions that participate in the student loan programs.

\footnotetext{
${ }^{13}$ The CUNY system is substantially more expensive, and arguably more stratified by ability, than the system under consideration in this paper. While purely speculative, this provides possible explanations for why Pell eligibility may impact college choice in this context but not in the CUNY context.

${ }^{14}$ This amount is less than the statutory discontinuity in Pell eligibility largely because of less-than-full-time enrollment.
} 


\section{Figure 3: Grant Amounts (\$) for Loan and No-Loan Schools}
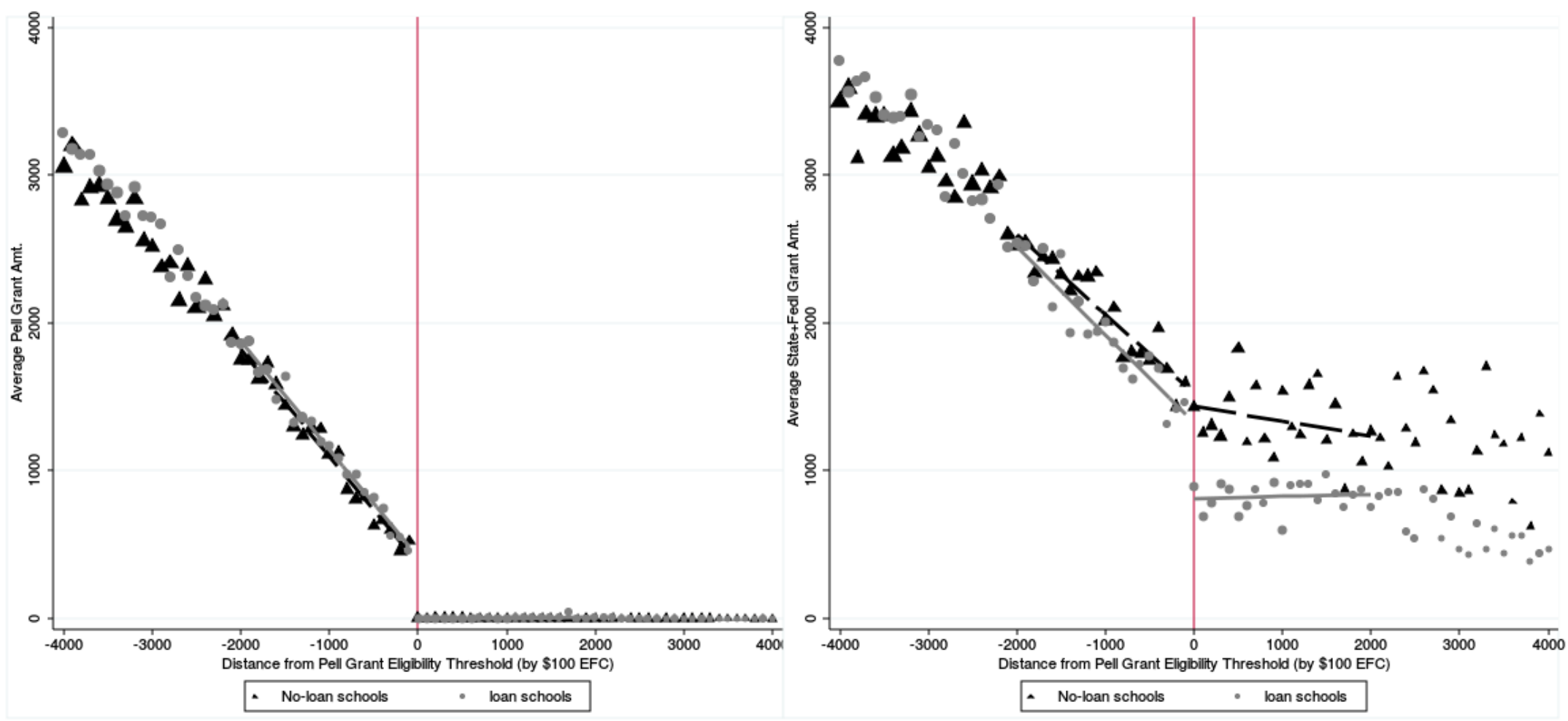

Note. Samples are restricted to 2008-2010 cohort students who have filed FAFSA, for whom race/ethnicity is not missing, and who are non-dual enrollees. Averages are plotted separately for loan schools (triangle points) and no-loan schools (circle points). Each point represents mean outcomes for students that fall within a bin of size $\$ 100 \mathrm{EFC}$. Only points within a $+/-\$ 4,000$ bandwidth are in the figure. Gray solid (loan schools) and black dashed (no-loan schools) lines are the linear fitted value of these points that fall within the $+/-\$ 2,000$ bandwidth. 
The left panel of Figure 4 shows student loan receipt by EFC. Of course, at no-loan schools, student loans are zero throughout the distribution. ${ }^{15}$ At loan schools, we see a sizable jump in average loan amounts for students just above the Pell eligibility threshold. Considering all aid together, the right panel shows that for neither institution type is there any discontinuity in total aid received. For no-loan schools, state grant aid smooths out the discontinuity in Pell, while for loan schools, the discontinuity is smoothed out by loans. (Also note that the higher state grant aid at no-loan schools does not completely make up for the lack of loans: students at no-loan schools receive substantially less in total aid than students at loan schools.)

Table 2 shows the regression results corresponding to the panels of Figure 5 (which immediately follows Table 2), with the top portion of the table showing results for loan schools and the bottom portion showing results for no-loan schools. Confirming what is visible in the pictures, there is a large discontinuity in Pell Grants in both cases, but at no-loan schools, there is no significant discontinuity in total grant aid, loans, or total aid. For loan schools, there is a significant discontinuity in total grant aid (coefficient $=\$ 560, p<.01$ ), but an equal-and-opposite discontinuity in loan aid (coefficient $=-\$ 592, p<.01$ ), leading to no discontinuity in total aid. ${ }^{16}$ The pattern of loan take-up at these schools replicates that found in previous research by Marx and Turner (2015), though it appears even more strongly in our sample.

For no-loan schools, which in our sample represent about half of the institutions but only about one-quarter of students enrolled, we have no first stage: Pell eligibility has no discontinuous effect on any treatment we expect to matter (unless we think a dollar of Pell Grants affects students differently than a dollar of state grants). ${ }^{17}$ Therefore, we limit our subsequent analyses to students attending only loan-offering schools, where we do observe a significant discontinuity in overall grant aid. Even at loan institutions, these findings alter how we think about the treatment. In interpreting the effects that follow, it is important to recognize that we are estimating the effect of receiving $\$ 500$ in grants instead of loans. ${ }^{18}$

\footnotetext{
${ }^{15}$ We suspect that the few observations off the line are either data errors or possibly students who switched institutions mid-year.

${ }^{16}$ Note that total aid includes some other small aid programs, so that it may be slightly more than the sum of grants and loans.

${ }^{17}$ In results not shown here, we can confirm that there are no impacts on any outcome when we run our models for students at no-loan institutions. Moreover, there is no discontinuity in the density of observations around the cutoff for these schools.

${ }^{18}$ Moreover, as noted by Marx and Turner (2015), these averages mask important heterogeneity, because everyone to the left of the cutoff qualifies for a $\$ 500$ Pell Grant, but to the right of the cutoff, some students take out large loans while others take out nothing. Thus, some students who are bumped just below the cutoff will experience an increase in total aid, while others may actually take up less total aid than if they had not been Pell-eligible.
} 


\section{Figure 4: Loan and Total Aid Amounts (\$) for Loan and No-Loan Schools}
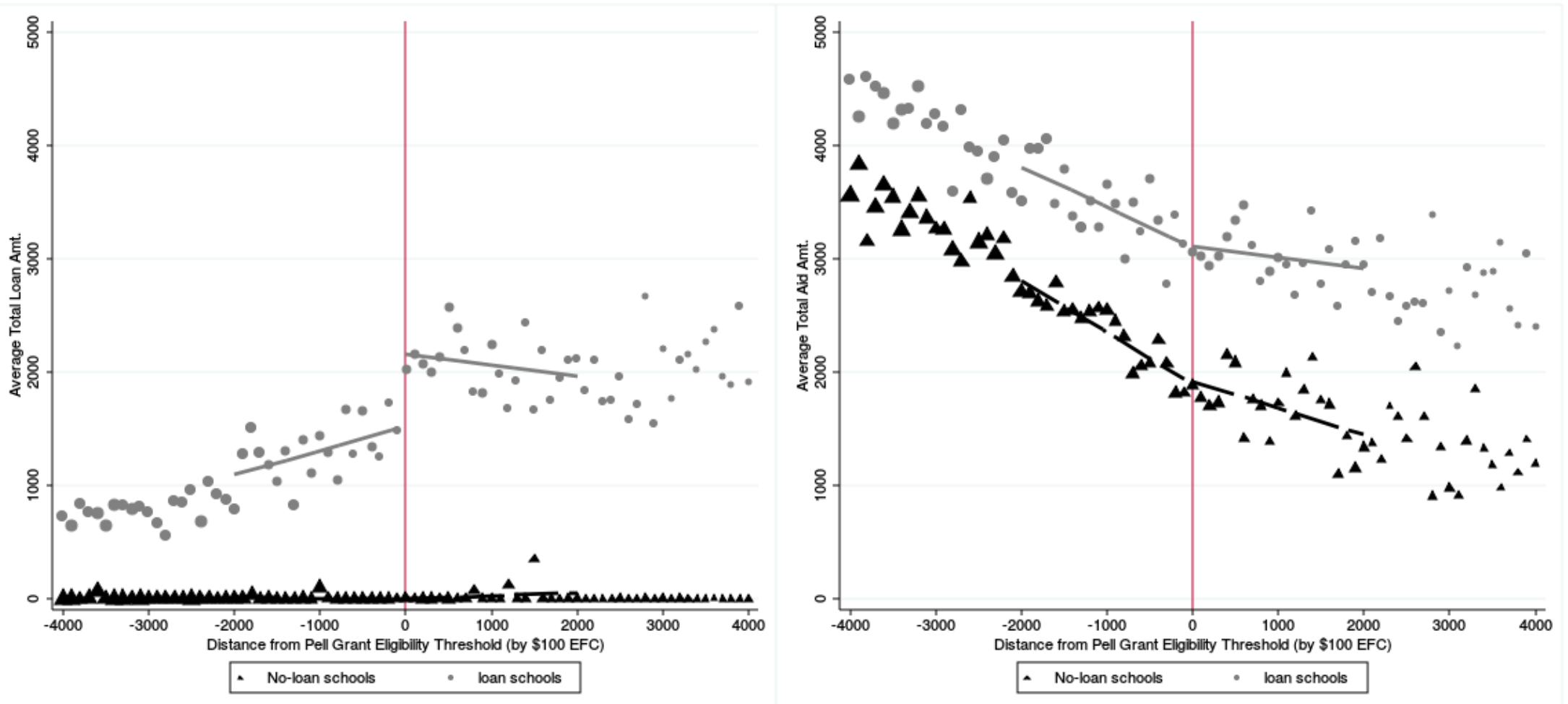

Note. Samples are restricted to 2008-2010 cohort students who have filed FAFSA, for whom race/ethnicity is not missing, and who are non-dual enrollees. Averages are plotted separately for loan schools (triangle points) and no-loan schools (circle points). Each point represents mean outcomes for students that fall within a bin of size $\$ 100 \mathrm{EFC}$. Only points within a $+/-\$ 4,000$ bandwidth are in the figure. Gray solid (loan schools) and black dashed (no-loan schools) lines are the linear fitted value of these points that fall within a $+/-\$ 2,000$ bandwidth. 
Table 2: RD Estimates of Effect of Pell Eligibility on Composition of Financial Aid Packages

\begin{tabular}{|c|c|c|c|c|c|c|c|c|c|c|c|c|c|c|c|c|}
\hline \multirow{2}{*}{$\begin{array}{l}\text { Outcome } \\
\text { Institutions Offering Federal Loans }\end{array}$} & \multirow[t]{2}{*}{$\begin{array}{l}\text { Mean Outcomes } \\
\text { Just Above Cutoff }\end{array}$} & \multicolumn{3}{|c|}{$\begin{array}{l}\text { (1) Basic } 2000 \mathrm{bw} . \\
\text { Coef. } \quad \text { (S.E.) } \\
\end{array}$} & \multicolumn{3}{|c|}{$\begin{array}{l}\text { (2) Without cov. } \\
\text { Coef. (S.E.) }\end{array}$} & \multicolumn{3}{|c|}{$\begin{array}{l}\text { (3) } 1000 \mathrm{bw} . \\
\text { Coef. } \quad \text { (S.E.) }\end{array}$} & \multicolumn{2}{|c|}{ (4) 4000bw. } & \multicolumn{4}{|c|}{$\begin{array}{l}\text { (5) } 4000 \text { bw, Quadratic } \\
\text { Coef. (S.E.) }\end{array}$} \\
\hline & & & & & & & & & & & & & & & & \\
\hline Amount of Pell received & $\$ 0$ & $\$ 459$ & (17) & $* * *$ & $\$ 467$ & (17) & $* * *$ & $\$ 442$ & $(20)$ & $* * *$ & $\$ 445$ & (16) & $* * *$ & $\$ 426$ & $(22)$ & $* * *$ \\
\hline Amount of Pell+State grants received & $\$ 869$ & $\$ 560$ & $(64)$ & $* * *$ & $\$ 574$ & $(66)$ & $* * *$ & $\$ 598$ & $(92)$ & $* * *$ & $\$ 413$ & (46) & $* * *$ & $\$ 513$ & $(69)$ & $* * *$ \\
\hline Amount of loans received & $\$ 1,953$ & $-\$ 592$ & (113) & $* * *$ & $-\$ 639$ & $(118)$ & $* * *$ & $-\$ 534$ & $(163)$ & $* * *$ & $-\$ 451$ & (79) & $* * *$ & $-\$ 574$ & $(120)$ & $* * *$ \\
\hline Amount of total aid received & $\$ 2,993$ & $\$ 89$ & $(129)$ & & $\$ 56$ & $(131)$ & & $\$ 201$ & $(185)$ & & $\$ 107$ & $(91)$ & & $\$ 33$ & $(137)$ & \\
\hline Sample size & 1,421 & & 5,753 & & & 5,753 & & & 2,828 & & & 11,944 & & & 11,944 & \\
\hline \multicolumn{17}{|l|}{ Institutions Not Offering Federal Loans } \\
\hline Amount of Pell received & $\$ 0$ & $\$ 434$ & $(25)$ & $* * *$ & $\$ 427$ & $(25)$ & $* * *$ & $\$ 409$ & $(32)$ & $* * *$ & $\$ 481$ & $(25)$ & $* * *$ & $\$ 435$ & $(34)$ & $* * *$ \\
\hline Amount of Pell+State grants received & $\$ 1,640$ & $\$ 132$ & $(105)$ & & $\$ 97$ & $(118)$ & & $\$ 66$ & $(151)$ & & $\$ 203$ & (77) & $* * *$ & $\$ 90$ & (116) & \\
\hline Amount of loans received & $\$ 4$ & $\$ 3$ & $(8)$ & & $\$ 6$ & $(8)$ & & $-\$ 4$ & (11) & & $-\$ 9$ & (9) & & $\$ 7$ & $(7)$ & \\
\hline Amount of total aid received & $\$ 2,044$ & $\$ 153$ & $(123)$ & & $\$ 113$ & $(136)$ & & $-\$ 40$ & $(180)$ & & $\$ 268$ & $(89)$ & $* * *$ & $\$ 100$ & $(136)$ & \\
\hline Sample size & 456 & & 2,102 & & & 2,102 & & & 1,048 & & & 4,421 & & & 4,421 & \\
\hline
\end{tabular}

Note. Samples are restricted to students in the 2008-2010 fall entry cohorts who filed FAFSA and for whom race/ethnicity is not missing. Top panel estimates use only loan schools and bottom panel estimates use only no-loan schools. Coefficients indicate beta values for indicator of treatment status (i.e., 1 if eligible for Pell and 0 otherwise). Huber-White robust standard errors are in parentheses. Columns 1 and 2 are for samples within $+/-\$ 2,000$ bandwidth, column 3 for $+/-\$ 1,000$ bandwidth, columns 4 and 5 for $+/-\$ 4,000$ bandwidth. All specifications control for cohort fixed effects. All columns except column 2 control for covariates - female, Black, Hispanic, Asian, American-Indian, age, income, dependent, dual enrollment, reading, writing, math score prior to entry, and flags on whether they have these test scores - and college fixed effects. All columns except for column 5 use local linear polynomial regression, while column 5 uses quadratic polynomial specification. Rectangular kernel is used in all specifications.

$* * * p<.01, * * p<.05, * p<.1$. 
Figure 5: Density Plot for Loan Schools (Top) and No-Loan Schools (Bottom)
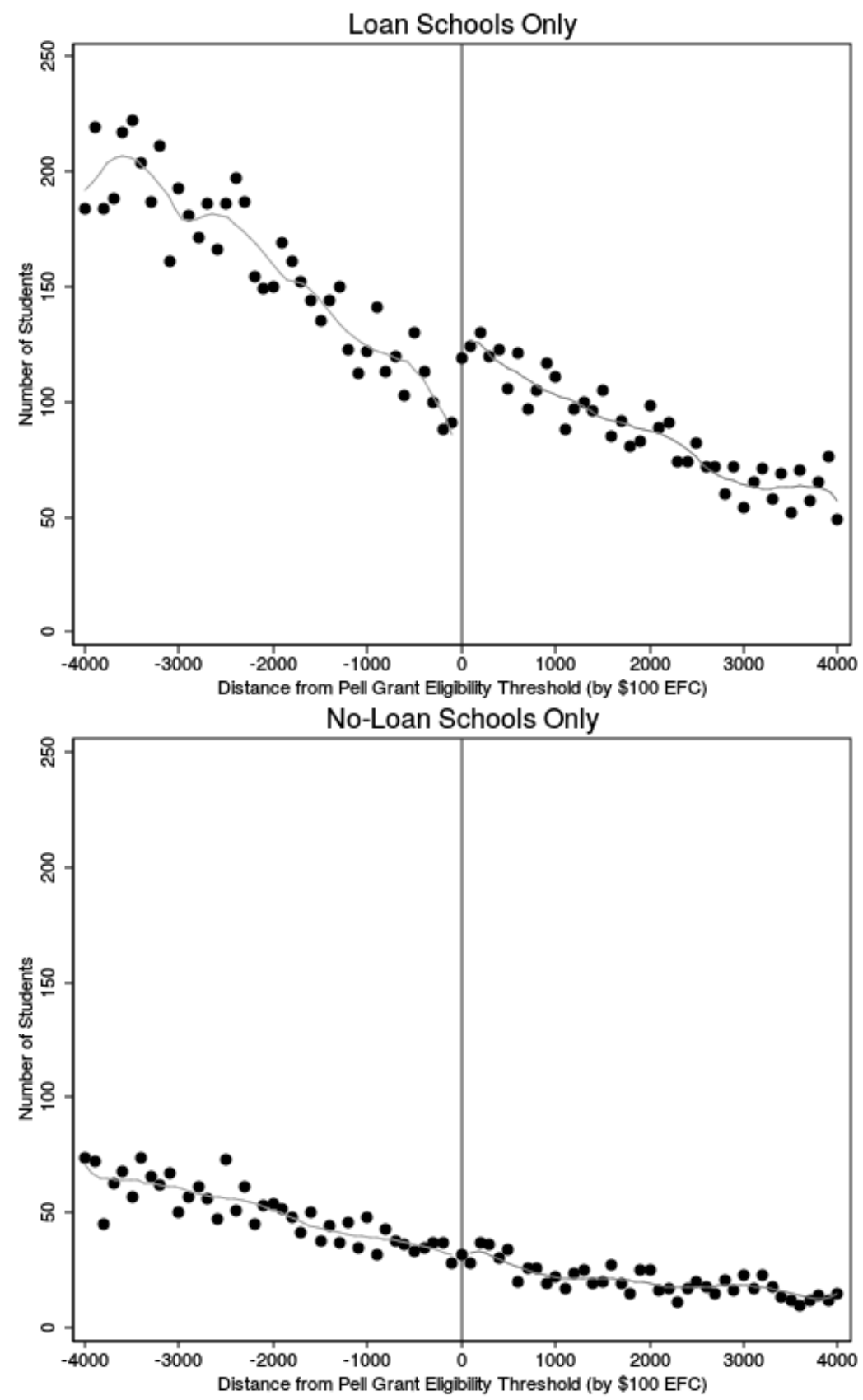

Note. Samples are restricted to 2008-2010 cohort students who have filed FAFSA, for whom race/ethnicity is not missing, who are non-dual enrollees, and only for students attending loan schools (top) or no-loan schools (bottom). Points represent number of students (sum count) that fall within a bin of size $\$ 100$ EFC. Points within a $+/-\$ 4,000$ bandwidth are included in the figure. Gray line is a local smoothed polynomial line with degree 2, using points within the $+/-\$ 4,000$ bandwidth. 


\section{Effects of Pell Grant Eligibility on Academic Outcomes and Labor Supply While Enrolled}

Table 3 shows our estimated impacts on academic outcomes and student labor supply. We examine re-enrollment and enrollment intensity, cumulative GPA and credits completed, and earnings during each of the first two years. We also examine GPA, credits attained, credentials, and transfer at the end of our three-year follow-up period. Note that for all outcomes, the difference in treatment is based on the first year difference in aid received; this does not measure the cumulative effect of receiving Pell for more than one year. ${ }^{19}$

With a few exceptions, our results are mostly in a positive direction, but small and not statistically significant. Among the notable exceptions are that we do find significant positive effects on full-time enrollment in the spring of the first year ( 5 percentage point increase from a base of 52 percent), full-time enrollment in the fall of the second year ( 7 percentage point increase from a base of 37 percent), and full-time enrollment in the spring of the second year (4 percentage point increase from a base of 33 percent). In contrast, we find a negative effect on summer term enrollment between Years 1 and 2 (of about 5 percentage points), which is surprising taking into account that these include years in which summer Pell Grants were available. $^{20}$

We also find consistently negative earnings effects during the first two years, though the reduction is only statistically significant in the first year. The negative earnings effects translate into about \$12-\$20 less per week and are of the same order of magnitude as the increase in grant aid for Pell-eligible students. These reductions are consistent with a story in which Pell allows students to shift their time allocation, perhaps an hour or two per week, from work to school. If true, we might expect to see increases not just in credits but in GPA. While effects on cumulative GPA were in a positive direction (between 0.06 to 0.08 points), they were not statistically significant (though they were very close by the end of our follow-up period).

Effects on cumulative credits earned, degree completion, and transfer measured three years after entry were generally in a positive direction and of a magnitude consistent with the positive effects observed in the time periods closest to the treatment. However, we do not have power to detect small effects on these distal outcomes, and it may simply be unrealistic to expect to see anything other than small effects given the treatment, which amounts to replacing \$500 in loans with $\$ 500$ in grants. In some respects, it might be considered surprising to find any effects of such a modest treatment.

\footnotetext{
${ }^{19}$ Though we cannot confirm it in our sample because we only have one year of aid data, Marx and Turner (2015) find no discontinuities in subsequent years' Pell Grants for students around the EFC cutoff in a given year.

${ }^{20}$ When we focus on the cohort most likely to have been eligible for summer Pell, the negative effect is no smaller.
} 
Table 3: RD Estimates of Effect of Pell Eligibility on Academic Outcomes and Student Labor Supply (Loan Schools)

\begin{tabular}{|c|c|c|c|c|c|c|c|c|c|c|c|c|c|c|c|c|}
\hline \multirow[b]{2}{*}{ Outcome } & \multirow{2}{*}{$\begin{array}{l}\text { Mean Outcomes } \\
\text { Just Above Cutoff }\end{array}$} & \multicolumn{2}{|c|}{ (1) Basic 2000bw. } & \multicolumn{3}{|c|}{ (2) Without cov. } & \multicolumn{3}{|c|}{ (3) $1000 \mathrm{bw}$. } & \multicolumn{3}{|c|}{ (4) $4000 \mathrm{bw}$. } & \multicolumn{4}{|c|}{ (5) 4000bw, Quadratic } \\
\hline & & Coef. & (S.E.) & & Coef. & (S.E.) & & Coef. & (S.E.) & & Coef. & (S.E.) & & Coef. & (S.E.) & \\
\hline \multicolumn{17}{|l|}{$\underline{\text { Year } 1 \text { Outcomes }}$} \\
\hline Enrolled full-time, Year 1 Fall & 0.657 & 0.020 & $(0.024)$ & & 0.030 & $(0.025)$ & & -0.003 & $(0.034)$ & & 0.002 & $(0.017)$ & & 0.008 & $(0.025)$ & \\
\hline Re-enrolled, Year 1 Spring & 0.842 & -0.016 & $(0.020)$ & & -0.012 & $(0.020)$ & & -0.028 & $(0.029)$ & & -0.001 & $(0.014)$ & & -0.048 & $(0.021)$ & $* *$ \\
\hline Enrolled full-time, Year 1 Spring & 0.520 & 0.048 & $(0.026)$ & $*$ & 0.058 & $(0.027)$ & $* *$ & 0.026 & $(0.037)$ & & 0.034 & $(0.018)$ & * & 0.019 & $(0.027)$ & \\
\hline Enrolled, Year 1 Summer & 0.290 & -0.046 & $(0.023)$ & $* *$ & -0.049 & $(0.024)$ & $* *$ & -0.091 & $(0.033)$ & $* * *$ & -0.022 & $(0.017)$ & & -0.065 & $(0.025)$ & $* * *$ \\
\hline Cum. GPA, End of Year & 2.473 & 0.061 & $(0.056)$ & & 0.060 & $(0.060)$ & & -0.027 & $(0.081)$ & & 0.007 & $(0.040)$ & & 0.044 & $(0.060)$ & \\
\hline Cum. Credits Completed, End of Year & 17.462 & 0.480 & $(0.559)$ & & 0.628 & $(0.589)$ & & -0.647 & $(0.808)$ & & -0.102 & $(0.390)$ & & -0.312 & $(0.591)$ & \\
\hline Cum. Year 1 earnings (Q4-Q3) & $\$ 4,873$ & $-\$ 806$ & $(393)$ & $* *$ & $-\$ 911$ & $(406)$ & $* *$ & $-\$ 710$ & $(538)$ & & $-\$ 727$ & $(282)$ & $* *$ & $-\$ 616$ & $(420)$ & \\
\hline \multicolumn{17}{|l|}{$\underline{\text { Year } 2 \text { Outcomes }}$} \\
\hline Re-enrolled, Year 2 Fall & 0.616 & 0.003 & $(0.026)$ & & 0.005 & $(0.026)$ & & -0.014 & $(0.037)$ & & 0.014 & $(0.018)$ & & -0.015 & $(0.027)$ & \\
\hline Enrolled full-time, Year 2 Fall & 0.371 & 0.074 & $(0.026)$ & $* * *$ & 0.079 & $(0.026)$ & $* * *$ & 0.065 & $(0.036)$ & $*$ & 0.036 & $(0.018)$ & $* *$ & 0.047 & $(0.027)$ & $*$ \\
\hline Re-enrolled, Year 2 Spring & 0.580 & 0.005 & $(0.026)$ & & 0.005 & $(0.026)$ & & 0.034 & $(0.037)$ & & -0.003 & $(0.018)$ & & -0.002 & $(0.028)$ & \\
\hline Enrolled full-time, Year 2 Spring & 0.328 & 0.044 & $(0.025)$ & $*$ & 0.047 & $(0.025)$ & $*$ & 0.044 & $(0.036)$ & & 0.021 & $(0.017)$ & & 0.026 & $(0.026)$ & \\
\hline Enrolled, Year 2 Summer & 0.226 & -0.004 & $(0.022)$ & & -0.004 & $(0.022)$ & & 0.013 & $(0.031)$ & & -0.011 & $(0.015)$ & & 0.005 & $(0.023)$ & \\
\hline Cum. GPA, End of Year & 2.401 & 0.074 & $(0.053)$ & & 0.084 & $(0.057)$ & & 0.027 & $(0.075)$ & & 0.022 & $(0.037)$ & & 0.051 & $(0.056)$ & \\
\hline Cum. Credits Completed, End of Year & 29.075 & 1.243 & (1.063) & & 1.463 & (1.123) & & -0.033 & $(1.530)$ & & 0.011 & $(0.745)$ & & -0.202 & $(1.127)$ & \\
\hline Cum. Year 2 earnings (Q4-Q3) & $\$ 5,323$ & $-\$ 534$ & $(445)$ & & $-\$ 627$ & $(455)$ & & $-\$ 552$ & $(620)$ & & $-\$ 364$ & $(318)$ & & $-\$ 385$ & $(475)$ & \\
\hline \multicolumn{17}{|l|}{ End of Year 3 Attainment Outcomes } \\
\hline Cum. GPA & 2.392 & 0.084 & $(0.052)$ & & 0.097 & $(0.056)$ & * & 0.046 & $(0.074)$ & & 0.019 & $(0.036)$ & & 0.059 & $(0.055)$ & \\
\hline Cum. credits earned & 35.205 & 1.741 & $(1.342)$ & & 1.937 & $(1.406)$ & & 0.946 & (1.935) & & -0.041 & $(0.940)$ & & 0.312 & $(1.423)$ & \\
\hline Ever transferred to $4-\mathrm{Yr}$ & 0.215 & 0.026 & $(0.021)$ & & 0.028 & $(0.022)$ & & -0.002 & $(0.031)$ & & 0.008 & $(0.015)$ & & 0.005 & $(0.023)$ & \\
\hline Earned any degree/cert & 0.206 & 0.010 & $(0.021)$ & & 0.016 & $(0.022)$ & & 0.000 & $(0.030)$ & & -0.011 & $(0.014)$ & & -0.012 & $(0.022)$ & \\
\hline Earned any degree/cert or transferred & 0.317 & 0.026 & $(0.024)$ & & 0.032 & $(0.025)$ & & 0.005 & $(0.035)$ & & -0.003 & $(0.017)$ & & 0.002 & $(0.025)$ & \\
\hline Sample size & 1,421 & & 5,753 & & & 5,753 & & & 2,828 & & & 11,944 & & & 11,944 & \\
\hline
\end{tabular}

Note. Samples are restricted to students in the 2008-2010 fall entry cohorts who filed FAFSA, for whom race/ethnicity is not missing, and among those attending loan schools. Coefficients indicate beta values for indicator of treatment status (i.e., 1 if eligible for Pell and 0 otherwise). Huber-White robust standard errors are in parentheses. Columns 1 and 2 are for samples within $\$ 2,000$ bandwidth, column 3 for $+/-\$ 1000$ bandwidth, columns 4 and 5 for $+/-\$ 4.000$ bandwidth. All specifications control for cohort fixed effects. All columns except column 2 control for covariates - female, Black, Hispanic, Asian, American-Indian, age, income, dependent, dual enrollment, reading, writing, math score prior to entry, and flags on whether they have these test scores-and college fixed effects. All columns except for column 5 use polynomial 1 degree specification, while column 5 uses quadratic polynomial specification. Rectangular kernel is used in all specifications.

$* * * p<.01, * * p<.05, * p<.1$. 


\section{Sensitivity Checks}

Optimal bandwidth. Tables 2 and 3 assess the sensitivity of our RD estimators using bandwidths of $1 / 2$ and two times our baseline bandwidth of $+/-\$ 2,000(+/-\$ 1,000$ and $+/-\$ 4,000$, respectively). The general pattern and sign of our main results holds across different bandwidths; however, both magnitude and significance level fluctuates. For the wide bandwidth, coefficients are generally smaller. We also calculated optimal bandwidths under three different methodscross-validation, IK, and CCT — separately for each outcome considered (see Appendix Table C2 for a summary of these results). ${ }^{21}$ Across outcomes, the average bandwidth suggested by crossvalidation and IK is around $+/-\$ 4,000$, while CCT suggests $+/-\$ 1,366$. Our baseline $+/-\$ 2,000$ bandwidth lies at the lower end for cross-validation and IK but at the upper end for CCT. Given these results, we think our baseline bandwidth of $+/-\$ 2,000$ bandwidth is reasonable.

Degree of polynomial. Misspecification of functional form can generate bias in our treatment estimator when calculating using linear regression (Lee \& Lemieux, 2010). Thus, the last column of Tables 2 and 3 also provide results using a quadratic specification (with our widest bandwidth). Again, the overall pattern of results is similar to baseline, but magnitudes shift and here we see some negative results (on spring/summer enrollment in Year 1) become significant. To explore optimal degree of polynomial, we conduct a degree of polynomial test following Lee and Lemieux (2010) non-parametric approach by adding bin dummies to the polynomial regression and testing for joint significance of the bin dummies (equivalent to an $F$ test using $R$-square from with and without the bin dummies regression, see Appendix Table C3 for full results). ${ }^{22}$ For each outcome, polynomial degree is determined by the degree whereby adding a higher order term no longer makes the bin dummies jointly significant. In some cases, bin dummies remain significant regardless of the order of polynomial. ${ }^{23}$ However, for variables where functional form does matter, a linear specification (polynomial of degree 1) is generally supported.

\section{Addressing Sample Selection Bias}

Limit analysis to subgroup where no discontinuity is present. We first use a subgroup selection method introduced by Calcagno and Long (2008) to address the problem of discontinuous density in a different RD setting. Calcagno and Long (2008) examine the impact of a test-score based assignment to remediation and find discontinuities in the density of observations around the cutoff at some institutions in their sample but not others. They conduct a

\footnotetext{
${ }^{21}$ For implementation, we use the rdbwselect_2014 function in the Stata rdrobust package (Calonico, Cattaneo, Farrell, \& Titiunik, 2017).

${ }^{22}$ Lee and Lemieux (2010) also use the Akaike information criterion (AIC) model selection for selection of degree of polynomial, however, they recommend a non-parametric $F$-test because of a lack of visibility to compare across different models (see Lee \& Lemieux, 2010, p. 326).

${ }^{23}$ We run this test including up to polynomial degree 6 . There are no major changes when we add these extra degrees.
} 
separate McCrary test for each institution and select only a subset of institutions with smooth densities for further analysis. When we follow a parallel approach, we find that nine smaller institutions exhibit no discontinuity in enrollments around the Pell Grant cutoff, while three large institutions do. Hereafter, we refer to the former group of institutions as the continuous group, and the latter as the non-continuous group.

Table 4, which examines how these two groups of institutions differ, is revealing in itself. Table 4 compares characteristics across the two subgroups, continuous and non-continuous institutions. Initially, we look at averages of pre-treatment covariates for all of our 2008-2010 cohorts. Students at non-continuous schools have more students of color (Black, Hispanic, and Asians) and substantially fewer White students. Non-continuous schools have more students who took remedial tests and have slightly higher writing and math scores, on average. ${ }^{24}$ Exploring counts and distance of local schools, we find striking differences between the two groups. On average, continuous schools have no community colleges, 0.4 four-year schools, and 1.8 forprofit institutions within 10 miles. Schools with discontinuous enrollment around the Pell cutoff also have no community colleges, but more four-year schools and many more for-profit schools within 10 miles (1.7 and 12.7, respectively). On average, a student at one of these schools is only about three miles away from either a four-year or a for-profit institution, while at continuous schools the nearest alternatives in these sectors are about 20 miles away. (As one might expect, non-continuous schools are located in more urban areas.) The large difference in nearby forprofit alternatives, in particular, suggests that perhaps the missing students who are eligible for Pell may have switched their enrollment to attend for-profit schools instead of community colleges. This would be consistent with Cellini's (2010) finding that increases in Pell awards increased enrollment at for-profit colleges. It is also possible, however, that students are using the Pell Grant to attend four-year colleges as well.

\footnotetext{
${ }^{24}$ One relatively large school from the continuous group has an essentially zero remedial test take-up rate, which seems to drive the average down for the continuous group.
} 
Table 4: Characteristics of Continuous Versus Non-Continuous Density (2008-2010 Cohort, Loan Schools)

\begin{tabular}{lcc}
\hline \hline & Continous Schools & Non-Continous Schools \\
\cline { 2 - 3 } Outcome & 0.528 & Mean \\
\hline Female (\%) & 0.223 & 0.511 \\
Black (\%) & 0.031 & 0.285 \\
Hispanic (\%) & 0.024 & 0.120 \\
Asian (\%) & 0.717 & 0.107 \\
White(\%) & 0.006 & 0.481 \\
American Indian (\%) & 21.616 & 0.006 \\
Age & 0.278 & 21.601 \\
Dual Enrollment & $\$ 38,752$ & 0.055 \\
Income & 0.688 & $\$ 44,754$ \\
Depend & 0.536 & 0.692 \\
Has Remedial Reading (\%) & 0.545 & 0.680 \\
Has Remedial Writing (\%) & 0.387 & 0.688 \\
Has Remedial Math (\%) & 81.553 & 0.614 \\
Remedial Reading placement score & 69.049 & 81.653 \\
Remedial Writing placement score & 34.190 & 71.703 \\
Remedial Math placement score & 3.864 & 36.007 \\
Prior Credits Attempted & 3.507 & 1.249 \\
Prior Credits Earned & $\$ 2,921$ & 1.040 \\
Prior Year Earnings (Q3-Q4-Q1-Q2) & 24,321 & $\$ 2,597$ \\
\hline Sample Size & & 43,221 \\
\hline Local Market & 0.0 & \\
Avg. Number of nearby 2-year public schools (N) & 27.7 & 0.0 \\
Avg. Distance to nearest 2-year school (miles) & 0.4 & 25.3 \\
Avg. Number of nearby 4-year schools (N) & 20.4 & 1.7 \\
Avg. Distance to the nearest 4-year school (miles) & 1.8 & 3.0 \\
Avg. Number of nearby for-profit schools (N) & 18.2 & 2.5 \\
Avg. Distance to nearest for-profit school (miles) & & \\
\hline & & \\
\hline
\end{tabular}

Note. Source is College Scorecard Data (n.d.). Top panel: We take all samples from 2008-2010 cohorts and average the characteristics by whether student's school is in the non-continuous or continuous group. Bottom panel: We define nearby schools as those located within less than 10 miles from our sample schools. Distance is calculated using latitude and longitude coordinates. All local market variables are averages for schools in the non-continuous or continuous group. 
Unfortunately, the large differences in demographics across the two groups of institutions make any differences in impacts hard to interpret. While it would be reassuring if our analyses held up within our subset of continuous-density schools, if they do not, it is not clear whether this indicates that our results are driven by selection, or simply that Pell Grants have heterogeneous effects for different student populations. Nonetheless, we present our results for these two subsets of schools separately. First, we check for continuity in the density for all students attending continuous schools as a whole in Figure $6 .{ }^{25}$ Figures 7 and 8 are similar graphical representations of grant amount, loan amount, and total aid amount around the cutoff as in Figures 3 and 4, but for the continuous group and the non-continuous group separately. Table 5 shows our estimated regression effects on financial aid packages (top four rows) are consistent with our main results in Table 2. However, for academic and labor market outcomes, we see distinctive regression results between continuous and non-continuous density groups. The general pattern is that few results are significant within the continuous group and some outcomes even have the opposite sign. The positive results that we observe in our main results appear concentrated within the three large institutions with non-continuous density around the Pell cutoff. The fact that results are concentrated in the group where selection bias is most severe is not reassuring, but for the reasons explained above, neither is it definitive. The two groups are very demographically different and it is possible that the effect of Pell Grant is larger for younger, non-White students with higher test scores.

\footnotetext{
${ }^{25}$ The fact that individual institutions pass the McCrary test separately does not guarantee that they will do so in the aggregate. We test and confirm that our continuous group passes the McCrary test as a whole.
} 
Figure 6: Density Plot for Continuous Schools (Top) and Non-Continuous Schools (Bottom)
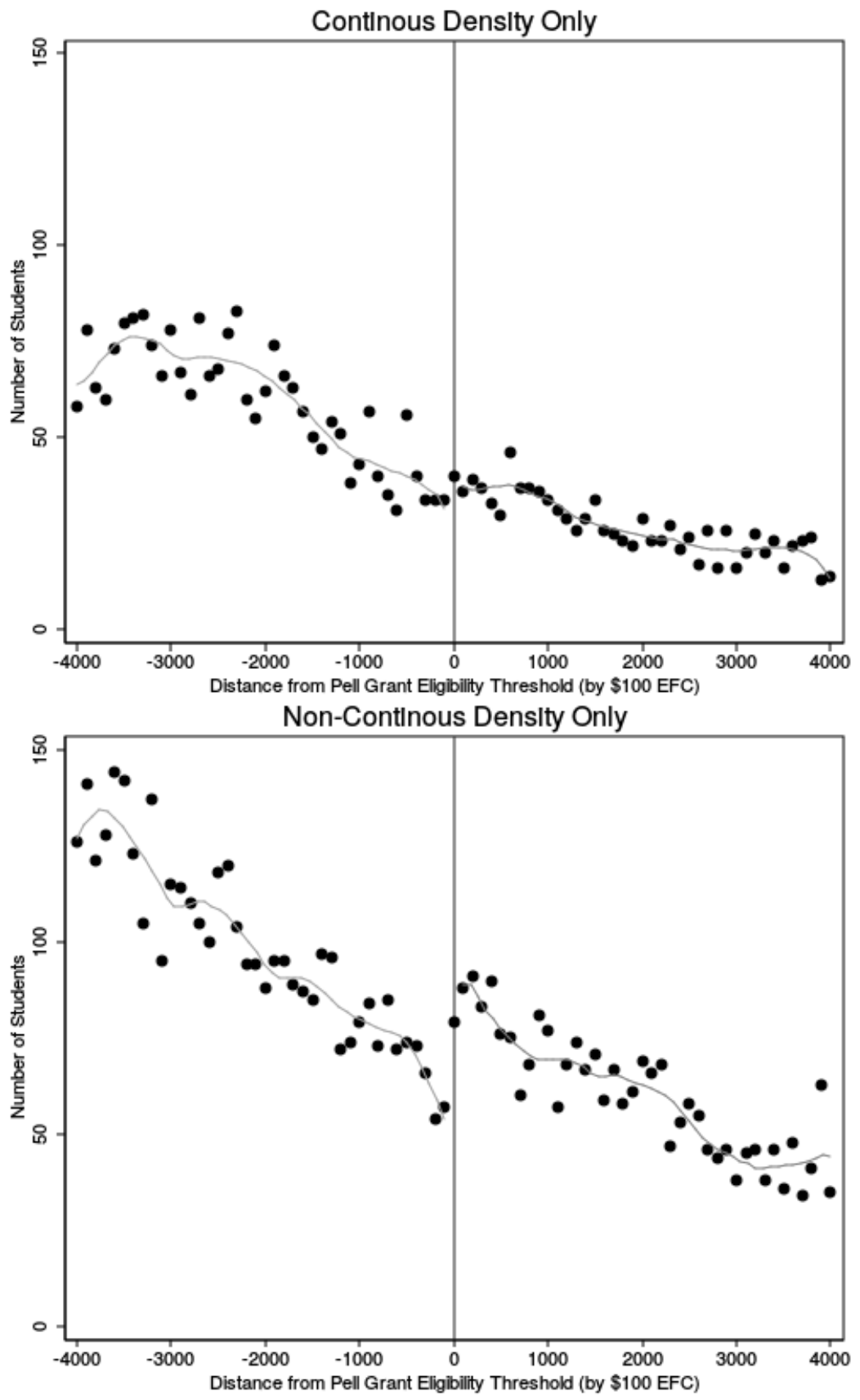

Note. Samples are restricted to 2008-2010 cohort students who have filed FAFSA, for whom race/ethnicity is not missing, who are non-dual enrollees, and who are attending loan schools. Points represent number of students (sum count) that fall within a bin of size $\$ 100$ EFC. Points within $+/-\$ 4,000$ bandwidth are included in the figure. Gray line is a local smoothed polynomial line with degree 2 , using points within the $+/-\$ 4,000$ bandwidth. 
Figure 7: Grant Amounts (\$) for Continuous and Non-Continuous Schools
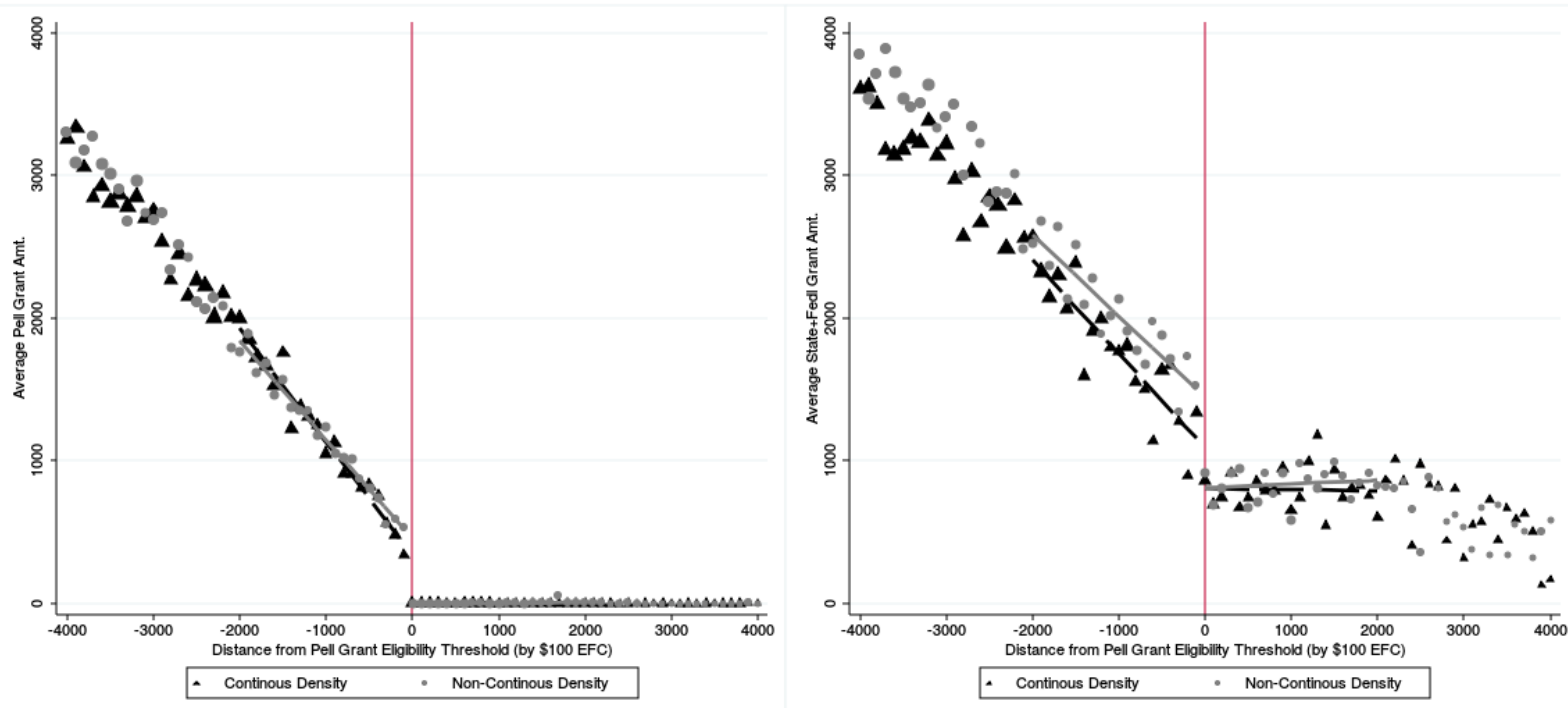

Note. Samples are restricted to 2008-2010 cohort students who have filed FAFSA, for whom race/ethnicity is not missing, and who are non-dual enrollees. Averages are plotted separately for continuous schools (triangle points) and non-continuous schools (circle points). Each point represents mean outcomes for students that fall within a bin of size $\$ 100 \mathrm{EFC}$. Only points within a $+/-$ $\$ 4,000$ bandwidth are in the figure. Gray solid (continuous schools) and black dashed (non-continuous schools) lines are the linear fitted value of these points that fall within a $+/-\$ 2,000$ bandwidth.

Figure 8: Loan and Total Aid Amounts (\$) for Continuous and Non-Continuous Schools
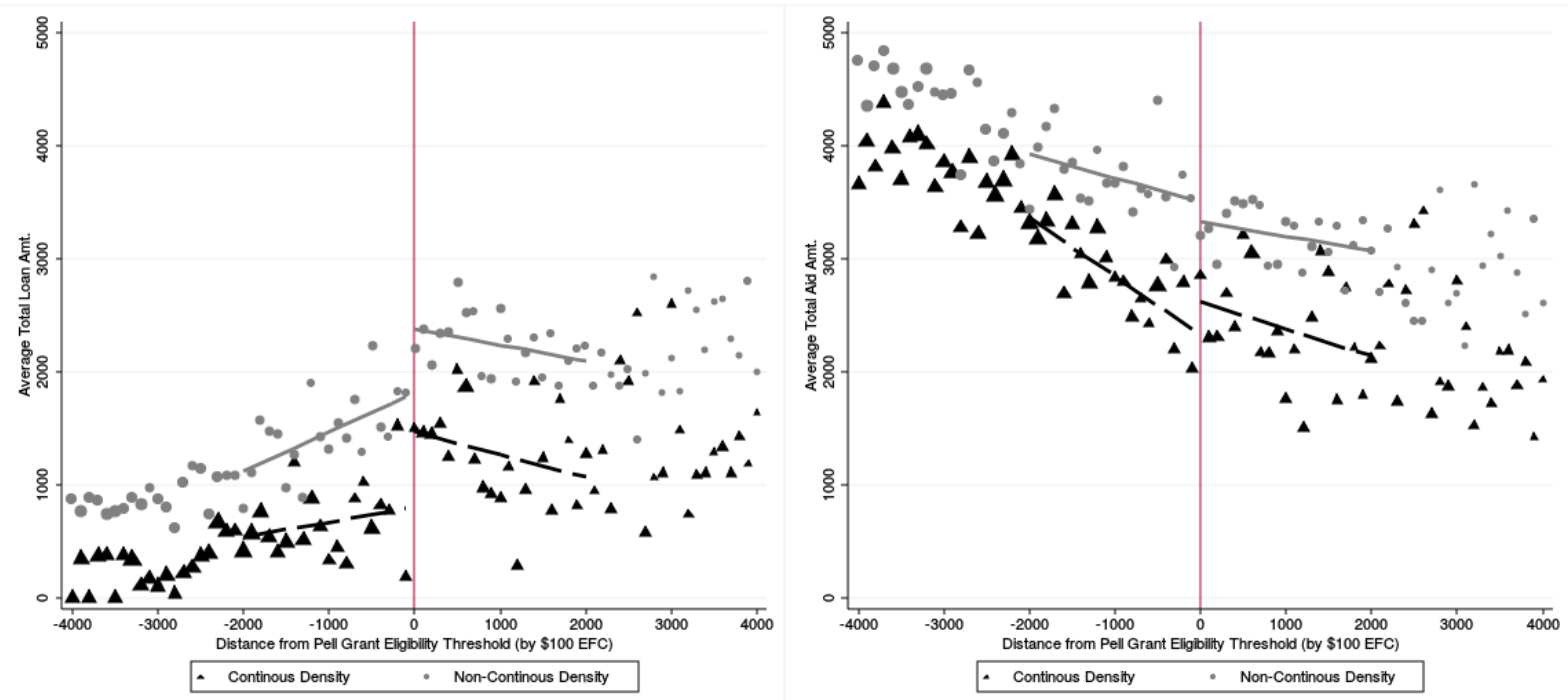

Note. Samples are restricted to 2008-2010 cohort students who have filed FAFSA, for whom race/ethnicity is not missing, and who are non-dual enrollees. Averages are plotted separately for continuous schools (triangle points) and non-continuous schools (circle points). Each point represents mean outcomes for students that fall within a bin of size $\$ 100$ EFC. Only points within a $+/-$ $\$ 4,000$ bandwidth are in the figure. Gray solid (continuous schools) and black dashed (non-continuous schools) lines are the linear fitted value of these points that fall within $\mathrm{a}+/-\$ 2,000$ bandwidth. 
Table 5: RD Estimates of Impact of First-Year Pell Eligibility (2008-2010 Cohort, Loan Schools, $\$ 2,000$ Bandwidth With Covariates)

\begin{tabular}{|c|c|c|c|c|c|c|c|c|}
\hline \multirow[b]{3}{*}{ Outcome } & \multicolumn{4}{|c|}{$\underline{\text { Continuous Density Schools }}$} & \multicolumn{4}{|c|}{ Non-Continuous Density Schools } \\
\hline & (1) Mean Outcomes & $(2)$ & (3) & (4) & (5) Mean Outcomes & (6) & (7) & (8) \\
\hline & Just Above Cutoff & Coef. & $($ S.E. $)$ & & Just Above Cutoff & Coef. & (S.E.) & \\
\hline Amount of Pell received & $\$ 0$ & $\$ 436$ & (25) & $* * *$ & $\$ 0$ & $\$ 485$ & (23) & $* * *$ \\
\hline Amount of Pell+State grants received & $\$ 955$ & $\$ 400$ & (90) & $* * *$ & $\$ 810$ & $\$ 697$ & (90) & $* * *$ \\
\hline Amount of loans received & $\$ 1,500$ & $-\$ 600$ & $(160)$ & $* * *$ & $\$ 2,263$ & $-\$ 559$ & (159) & $* * *$ \\
\hline Amount of total aid received & $\$ 2,664$ & $-\$ 72$ & (183) & & $\$ 3,217$ & $\$ 245$ & (179) & \\
\hline \multicolumn{9}{|l|}{$\underline{\text { Year } 1 \text { Outcomes }}$} \\
\hline Enrolled full-time, Year 1 Fall & 0.683 & 0.022 & $(0.035)$ & & 0.639 & 0.021 & $(0.032)$ & \\
\hline Re-enrolled, Year 1 Spring & 0.837 & -0.052 & $(0.031)$ & $*$ & 0.845 & 0.017 & $(0.025)$ & \\
\hline Enrolled full-time, Year 1 Spring & 0.542 & 0.012 & $(0.039)$ & & 0.505 & 0.076 & $(0.034)$ & $* *$ \\
\hline Enrolled, Year 1 Summer & 0.284 & -0.066 & $(0.035)$ & $*$ & 0.294 & -0.034 & $(0.032)$ & \\
\hline Cum. GPA, End of Year & 2.522 & 0.064 & $(0.082)$ & & 2.438 & 0.059 & $(0.078)$ & \\
\hline Cum. Credits Completed, End of Year & 18.075 & -0.532 & $(0.864)$ & & 17.043 & 1.244 & $(0.728)$ & * \\
\hline Cum. Year 1 earnings (Q4-Q3) & $\$ 4,643$ & $\$ 38$ & $(558)$ & & $\$ 5,030$ & $-\$ 1,269$ & $(545)$ & $* *$ \\
\hline \multicolumn{9}{|l|}{ Year 2 Outcomes } \\
\hline Re-enrolled, Year 2 Fall & 0.584 & -0.004 & $(0.040)$ & & 0.637 & 0.014 & $(0.034)$ & \\
\hline Enrolled full-time, Year 2 Fall & 0.367 & 0.045 & $(0.039)$ & & 0.373 & 0.094 & $(0.034)$ & $* * *$ \\
\hline Re-enrolled, Year 2 Spring & 0.537 & 0.018 & $(0.040)$ & & 0.609 & -0.001 & $(0.034)$ & \\
\hline Enrolled full-time, Year 2 Spring & 0.317 & 0.028 & $(0.037)$ & & 0.335 & 0.055 & $(0.034)$ & \\
\hline Enrolled, Year 2 Summer & 0.189 & 0.008 & $(0.031)$ & & 0.251 & -0.008 & $(0.030)$ & \\
\hline Cum. GPA, End of Year & 2.464 & 0.081 & $(0.077)$ & & 2.357 & 0.069 & $(0.071)$ & \\
\hline Cum. Credits Completed, End of Year & 29.140 & 0.148 & $(1.608)$ & & 29.030 & 2.186 & $(1.412)$ & \\
\hline Cum. Year 2 earnings (Q4-Q3) & $\$ 5,270$ & $\$ 423$ & $(652)$ & & $\$ 5,359$ & $-\$ 1,132$ & $(607)$ & $*$ \\
\hline \multicolumn{9}{|l|}{ End of Year 3 Attainment Outcomes } \\
\hline Cum. GPA & 2.454 & 0.076 & $(0.077)$ & & 2.349 & 0.090 & $(0.070)$ & \\
\hline Cum. credits earned & 34.133 & 1.095 & $(1.986)$ & & 35.937 & 2.512 & $(1.814)$ & \\
\hline Ever transferred to $4-\mathrm{Yr}$ & 0.243 & -0.022 & $(0.033)$ & & 0.197 & 0.056 & $(0.029)$ & $* *$ \\
\hline Earned any degree/cert & 0.255 & -0.009 & $(0.033)$ & & 0.173 & 0.018 & $(0.027)$ & \\
\hline Earned any degree/cert or transferred & 0.378 & -0.011 & $(0.037)$ & & 0.275 & 0.045 & $(0.031)$ & \\
\hline Sample size & 577 & & & & 844 & 3,2 & & \\
\hline
\end{tabular}

Note. Samples are restricted to 2008-2010 fall entry cohort students who filed FAFSA, for whom race/ethnicity is not missing, and who are attending loan schools. Columns 1-4 further restrict to the subset of schools that has continuous density by McCrary (2008) test. Columns 5-8 restrict to the subset of schools that fails continuous density test by McCrary (2008). Coefficients indicate beta values for indicator of treatment status (i.e., 1 if eligible for Pell and 0 otherwise). Huber-White robust standard errors are in parentheses. Both regressions are within a $+/-$ $\$ 2,000$ bandwidth except mean outcomes (columns 1 and 5) and control for cohort fixed effects for covariatesfemale, Black, Hispanic, Asian, American-Indian, age, income, dependent, dual enrollment, reading, writing, math score prior to entry, and flags on whether they have these test scores - and college fixed effects. Local linear polynomial is used with rectangular kernel in all specifications.

$* * * p<.01, * * p<.05, * p<.1$. 
Bounding analysis. Another way to account for potential selection bias is to bound our estimates as introduced by Gerard et al. (2016). GRR introduce a way to identify partial treatment effects through estimating upper/lower bounds by making worst/best assumptions about the missing population. ${ }^{26}$ For further details about this methodology, see Appendix B. GRR define "selectors" as those individuals, in this context, whose enrollment decision is influenced by whether or not they fall above or below the Pell cutoff. In this case, the selectors who fall below the cutoff, and hence qualify for Pell, are unobserved. Above the cutoff are a mix of non-selectors and selectors who would have enrolled elsewhere had they qualified for Pell. The goal of the GRR method is to estimate upper and lower bounds of the effects for only nonselectors by trimming the mixed side (in this case, above the cutoff, which includes both selectors and non-selectors) of the estimated proportion of selectors.

We first estimate the proportion of selectors $(\tau)$ by calculating the jump in enrollment at the cutoff from the height of the density curve using local polynomial smoothing with rectangular kernel (and degree 1 polynomial). Second, assuming selectors have the best (worst) observed outcomes, the upper (lower) bound is estimated by the difference in expectation of outcome between the left and right side of the cutoff, where the side with more observations has been trimmed of observations below (above) the $\tau$ (or, respectively, $1-\tau$ ) quantile. See Appendix B for further details.

We perform two versions of this bounding analysis. First, we trim separately based on for each individual outcome, as indicated by the GRR method. This produces the widest bounds but is overly conservative in practice because different individuals are trimmed from the sample for each outcome (it is not the case that the best students on one outcome are the best students on all outcomes). So, as an alternative, we also examine results when we trim the sample just once, based on cumulative GPA in the first semester of the first year, and then calculate bounds on all outcomes using that same sample.

Table 6 reproduces our baseline regression estimates $(+/-\$ 2,000$ bandwidth including covariate controls), and then shows the results from these two versions of our bounding analysis. As expected, the GRR bounds in column 2 (in which the sample is trimmed separately for each sample) are very wide. In column 3 , we tighten our bounds by trimming only once, based on a single outcome variable, then calculating bounds on different outcome variables using that same trimmed sample. We choose cumulative GPA in the fall semester of entrance to college, under the logic that whatever are the unobservable factors that influence enrollment decisions (e.g., student motivation) may correlate with academic performance as observed after enrollment. Our bounding results (column 3 ) are tighter with more zero-excluding bounds (indicated in bold brackets). Effects of Pell eligibility on financial aid packaging holds with all zero-excluding bounds. The bounds on full-time enrollment still fail to exclude zero, but is shifted toward more

\footnotetext{
${ }^{26}$ The GRR-bounding exercise is an extension to Lee's (2009) bounding exercise in the Sharp RD case. GRR require two additional assumptions regarding what they call the "selectors" (those students whose enrollment decisions shift as a result of their Pell eligibility): that the direction of selection is one-sided and that the conditional density is left-differentiable.
} 
positive impacts. Academic earnings and summer earnings in both Year 1 and Year 2 remain negative with bounds that exclude zero.

Table 6: GRR Bounds on RD Estimates (2008-2010 Cohort, Loan Schools Only)

\begin{tabular}{|c|c|c|c|c|c|c|}
\hline \multirow[b]{2}{*}{ Outcome } & \multicolumn{2}{|c|}{ Original Estimates } & \multicolumn{2}{|c|}{$\begin{array}{c}\text { Trim by each } \\
\text { outcome }\end{array}$} & \multicolumn{2}{|c|}{$\begin{array}{c}\text { (3) } \\
\text { Trim by cum. GPA } \\
\text { fall semester, 1st } \\
\text { year }\end{array}$} \\
\hline & Coef & (S.E.) & [low, & upper] & [low, & upper] \\
\hline Amount of Pell received & $\$ 459$ & $(17)$ & - & - & - & - \\
\hline Amount of Pell+State grants received & $\$ 560$ & $(64)$ & {$[\$ 236$,} & $\$ 1,143]$ & {$[\$ 377$,} & $\$ 661]$ \\
\hline Amount of loans received & $-\$ 592$ & $(113)$ & {$[\$-1,909$} & $\$ 847]$ & {$[\$-692$,} & $\$-442]$ \\
\hline Amount of total aid received & $\$ 89$ & (129) & {$[\$-1,176$, } & $\$ 1,599]$ & {$[\$ 73$,} & \$98] \\
\hline \multicolumn{7}{|l|}{$\underline{\text { Year I Outcomes }}$} \\
\hline Enrolled full-time, Year 1 Fall & 0.020 & $(0.024)$ & {$[-0.213$} & $0.374]$ & {$[-0.017$} & $0.021]$ \\
\hline Re-enrolled, Year 1 Spring & -0.016 & $(0.020)$ & {$[-0.156$} & $0.432]$ & {$[-0.099$} & $0.029]$ \\
\hline Enrolled full-time, Year 1 Spring & 0.048 & $(0.026)$ & {$[-0.248$} & $0.339]$ & {$[-0.061$} & $0.085]$ \\
\hline Enrolled, Year 1 Summer & -0.046 & $(0.023)$ & {$[-0.546$} & $0.041]$ & {$[-0.125$} & $-0.011]$ \\
\hline Cum. GPA, End of Year & 0.061 & $(0.056)$ & {$[-0.569$} & $0.577]$ & {$[-0.516$} & $0.511]$ \\
\hline Cum. Credits Completed, End of Year & 0.480 & $(0.559)$ & {$[-5.236$} & $6.610]$ & {$[-3.885$} & $3.048]$ \\
\hline Cum. Year 1 Earnings (Q4-Q3) & $-\$ 312$ & $(192)$ & {$[\$-2,749$} & $\$ 3,630]$ & {$[\$-347$,} & $\$-121]$ \\
\hline \multicolumn{7}{|l|}{$\underline{\text { Year } 2 \text { Outcomes }}$} \\
\hline Re-enrolled, Year 2 Fall & 0.003 & $(0.026)$ & {$[-0.323$} & $0.264]$ & {$[-0.074$} & $0.062]$ \\
\hline Enrolled full-time, Year 2 Fall & 0.074 & $(0.026)$ & {$[-0.343$} & $0.244]$ & {$[-0.017$} & $0.121]$ \\
\hline Re-enrolled, Year 2 Spring & 0.005 & $(0.026)$ & {$[-0.394$} & $0.193]$ & {$[-0.091$} & $0.067]$ \\
\hline Enrolled full-time, Year 2 Spring & 0.044 & $(0.025)$ & {$[-0.424$} & $0.163]$ & {$[-0.027$} & $0.090]$ \\
\hline Enrolled, Year 2 Summer & -0.004 & $(0.022)$ & {$[-0.491$} & $0.096]$ & {$[-0.044$} & $0.023]$ \\
\hline Cum. GPA, End of Year & 0.074 & $(0.053)$ & {$[-0.509$} & $0.605]$ & {$[-0.447$} & $0.453]$ \\
\hline Cum. Credits Completed, End of Year & 1.243 & $(1.063)$ & {$[-9.128$} & $13.378]$ & {$[-6.046$} & $5.703]$ \\
\hline Cum. Year 2 Earnings (Q4-Q3) & $-\$ 281$ & $(224)$ & {$[\$-2,865$} & $\$ 4,477]$ & [\$-381, & $\$-54]$ \\
\hline \multicolumn{7}{|l|}{ End of Year 3 Attainment Outcomes } \\
\hline Cum. GPA & 0.084 & $(0.052)$ & {$[-0.475$} & $0.606]$ & {$[-0.421$} & $0.451]$ \\
\hline Cum. credits earned & 1.741 & $(1.342)$ & {$[-11.665$} & 17.283] & {$[-6.900$} & $6.815]$ \\
\hline Ever trans ferred to $4-\mathrm{Yr}$ & 0.026 & $(0.021)$ & {$[-0.393$} & $0.194]$ & {$[-0.048$} & $0.094]$ \\
\hline Earned any degree/cert & 0.010 & $(0.021)$ & {$[-0.516$} & $0.072]$ & {$[-0.090$} & $0.068]$ \\
\hline Earned any degree/cert or transferred & 0.026 & $(0.024)$ & {$[-0.406$} & $0.181]$ & {$[-0.091$} & $0.108]$ \\
\hline Sample Size & 5,753 & 5,753 & 4,576 & 4,576 & 4,431 & 4,448 \\
\hline
\end{tabular}

Note. Samples are restricted to students in 2008-2010 fall entry cohorts who filed FAFSA, for whom race/ethnicity is not missing, and who are attending loan schools. Column 1 is from Table 2 and Table 3 . Columns 2 and 3 are bound estimates using GRR bounding exercise. Square brackets indicate lower and upper bounds of treatment effect after adjusting for sample selection bias. Column 2 trims and run a single regression separately for each outcome variable. Column 3 trims using a single variable, cumulative GPA fall semester of 1st year, and runs multiple regressions on different outcomes. All regressions are specified using local linear regression within $+/-\$ 2,000$ bandwidth with rectangular kernel, controls for cohort fixed effects, controls for covariates-female, Black, Hispanic, Asian, American-Indian, age, income, dependent, dual enrollment, reading, writing, math score prior to entry, and flags on whether they have these test scores — and controls for college fixed effects. 


\section{Discussion and Conclusion}

In this paper, we examine the effect of being eligible for Pell on financial aid packages, student outcomes, and labor supply among those community college students in a single state who are around the Pell Grant eligibility cutoff. First, we find that even at community colleges that have relatively little institutional aid to distribute, non-Pell aid awards are influenced by differences in Pell eligibility. Moreover, the pattern of response is distinctive depending on whether an institution offers federal student loans: for schools that offer loans, students who just miss qualifying for Pell borrow more (almost equivalent to Pell eligibility at the cutoff), such that students just above and below the Pell cutoff receive similar amounts of aid in total. For schools that do not offer loans, students who do not qualify for Pell receive higher state grants to compensate.

We next examine the effect of receiving a modest Pell grant (instead of loans) for students attending loan-offering schools. We find that students who just barely qualify for Pell are more likely to enroll full-time (about 4-7 percentage points more likely, depending upon the term) and at the same time reduce their labor supply by about \$12-20 per week. These patterns are consistent with a story in which Pell allows students to shift their time allocation, perhaps an hour or two per week, from work to school.

We also find a discontinuity in enrollments around the Pell cutoff (within loan-offering schools), which suggests that Pell eligibility may independently affect enrollment decisions as well. We find that this discontinuity in enrollments is concentrated at three large urban community colleges, which have a lot of local market competition, particularly from for-profit institutions.

Unfortunately, this pattern of enrollments may introduce bias into our regression discontinuity estimates. To examine this, we follow two methods in the literature: re-estimating impacts only for the subset of schools with continuous density through the cutoff, and a bounding analysis that makes extreme assumptions about the missing population. In both cases, our results are not entirely robust. While this is not reassuring, neither does it provide affirmative evidence that our main results are biased. Our best guess regarding the likely effects of receiving a modest Pell, in comparison to an equivalent amount of additional loans, is still drawn from our main results in Tables 2 and 3, which control for a rich set of observable characteristics at entry. Still, the lack of robustness suggests that these results should be interpreted cautiously and alongside evidence from other studies.

Our research has two implications. First, even at community colleges, which typically have very little "institutional" aid to distribute, institutions may have discretion to determine how Pell interacts with other state and federal aid programs. In our sample, we find a complex web of interactions, with state grants smoothing over the discontinuity in the Pell schedule at no-loan schools, and loans smoothing over the discontinuity at loan schools. Second, although the resulting treatment is relatively small-essentially implying a shift of $\$ 500$ from loans to 
grants - we nonetheless find some evidence that this alters some student behaviors. Students who are just below the cutoff (receiving Pell) seem to shift their time allocation, reducing work while increasing their enrollment intensity; we find significant increases in full-time enrollment and suggestive (but not significant) evidence of increases in GPAs. Moreover, we find indirect evidence that Pell eligibility may alter students' initial enrollment choices: students just barely eligible for Pell are less likely to show up in our sample of community college enrollees. 


\section{References}

Baum, S., \& Ma, J. (2011). Trends in college pricing 2010. New York, NY: The College Board.

Benson, J., \& Goldrick-Rab, S. (2011). Putting college first: How social and financial capital impact labor market participation among low-income undergraduates. Unpublished manuscript.

Bettinger, E. (2004). How financial aid affects persistence. In C. M. Hoxby (Ed.), College choices: The economics of where to go, when to go, and how to pay for it (pp. 207-238). Chicago, IL: University of Chicago Press.

Bettinger, E., Long, B. T., Oreopoulos, P., \& Sanbonmatsu, L. (2012). The role of application assistance and information in college decisions: Results from the H\&R Block FAFSA experiment. The Quarterly Journal of Economics, 127(3), 1205-1242.

Bettinger, E., \& Williams, B. (2013). Federal and state financial aid during the great recession. In J. Brown \& C. M. Hoxby (Eds.), How the financial crisis and great recession affected higher education (pp. 235-262). Cambridge, MA: National Bureau of Economic Research.

Boadway, R., \& Tremblay, J. F. (2012). Reassessment of the Tiebout model. Journal of Public Economics, 96(11), 1063-1078.

Calcagno, J. C., \& Long, B. T. (2008). The impact of postsecondary remediation using a regression discontinuity approach: Addressing endogenous sorting and noncompliance (NBER Working Paper No. 14194). Cambridge, MA: National Bureau of Economic Research.

Calonico, S., Cattaneo, M. D., Farrell, M. H., \& Titiunik, R. (2017). rdrobust: Software for regression discontinuity designs. Forthcoming in Stata Journal. Retrieved from http://www-personal.umich.edu/ cattaneo/papers/Calonico-Cattaneo-FarrellTitiunik_2017_Stata.pdf

Calonico, S., Cattaneo, M. D., \& Titiunik, R. (2014). Robust nonparametric confidence intervals for regression-discontinuity designs. Econometrica, 82(6), 2295-2326.

Cellini, S. R. (2010). Financial aid and for-profit colleges: Does aid encourage entry? Journal of Policy Analysis and Management, 29(3), 526-552.

College Scorecard Data. (n.d.) Data insights. Retrieved from https://collegescorecard.ed.gov/data/

Deming, D., \& Dynarski, S. (2009). Into college, out of poverty? Policies to increase the postsecondary attainment of the poor (NBER Working Paper No.15387). Cambridge, MA: National Bureau of Economic Research. 
Denning, J. T. (2016). Born under a lucky star: Financial aid, college completion, labor supply, and credit constraints. Unpublished manuscript presented at annual Association for Education Finance and Policy conference. Retrieved from https://aefpweb.org/sites/default/files/webform/41/BornUnderALuckyStar.pdf

DesJardins, S. L., \& McCall, B. P. (2008). The impact of the gates millennium scholars program on the retention, college finance-and work-related choices, and future educational aspirations of low-income minority students. Unpublished manuscript.

Dynarski, S., \& Scott-Clayton, J. E. (2006). The cost of complexity in federal student aid: Lessons from optimal tax theory and behavioral economics (NBER Working Paper No. 12227). Cambridge, MA: National Bureau of Economic Research.

Dynarski, S., Scott-Clayton, J., \& Wiederspan, M. (2013). Simplifying tax incentives and aid for college: Progress and prospects. In J. Brown (Ed.), Tax policy and the economy, volume 27 (pp. 161-201). Chicago, IL: University of Chicago Press.

Dynarski, S., \& Wiederspan, M. (2012). Student aid simplification: Looking back and looking ahead (NBER Working Paper No. 17834). Cambridge, MA: National Bureau of Economic Research.

Fan, J., \& Gijbels, I. (1996). Local polynomial modelling and its applications: Monographs on statistics and applied probability 66. Boca Raton, FL: CRC Press.

Gelman, A., \& Imbens, G. W. (2014). Why high-order polynomials should not be used in regression discontinuity designs (NBER Working Paper No. 20405). Cambridge, MA: National Bureau of Economic Research.

Gerard, F., Rokkanen, M., \& Rothe, C. (2016). Identification and inference in regression discontinuity designs with a manipulated running variable (CEPR Discussion Paper No. DP11048). Retrieved from SSRN website: http://ssrn.com/abstract=2717597

Goldrick-Rab, S., Kelchen, R., Harris, D. N., \& Benson, J. (2016). Reducing income inequality in educational attainment: Experimental evidence on the impact of financial aid on college completion. American Journal of Sociology, 121(6), 1762-1817.

Hahn, J., Todd, P., \& Van der Klaauw, W. (2001). Identification and estimation of treatment effects with a regression-discontinuity design. Econometrica, 69(1), 201-209.

Hansen, W. L. (1983). Impact of student financial aid on access. Proceedings of the Academy of Political Science, 35(2), 84-96.

Imbens, G. W., \& Kalyanaraman, K. (2012). Optimal bandwidth choice for the regression discontinuity estimator. The Review of Economic Studies, 79(3), 933-959.

Imbens, G. W., \& Lemieux, T. (2008). Regression discontinuity designs: A guide to practice. Journal of Econometrics, 142(2), 615-635. 
Johnson, W. R. (1988). Income redistribution in a federal system. The American Economic Review, 78(3), 570-573.

Kane, T. J. (1995). Rising public college tuition and college entry: How well do public subsidies promote access to college? (NBER Working Paper No. 5164). Cambridge, MA: National Bureau of Economic Research.

Lee, D. S. (2009). Training, wages, and sample selection: Estimating sharp bounds on treatment effects. The Review of Economic Studies, 76(3), 1071-1102.

Lee, D. S., \& Lemieux, T. (2010). Regression discontinuity designs in economics. Journal of Economic Literature, 48(2), 281-355.

Long, B. T. (2008). What is known about the impact of financial aid? Implications for policy (NCPR Working Paper). New York, NY: National Center for Postsecondary Research.

Ludwig, J., \& Miller, D. L. (2005). Does Head Start improve children's life chances? Evidence from a regression discontinuity design (NBER Working Paper No. 11702). Cambridge, MA: National Bureau of Economic Research.

Marx, B. M., \& Turner, L. J. (2015). Borrowing trouble? Student loans, the cost of borrowing, and implications for the effectiveness of need-based grant aid (NBER Working Paper No. 20850). Cambridge, MA: National Bureau of Economic Research.

McCrary, J. (2008). Manipulation of the running variable in the regression discontinuity design: A density test. Journal of Econometrics, 142(2), 698-714.

McCrary, J., \& Royer, H. (2003). Does maternal education affect infant health? A regression discontinuity approach based on school age entry laws. Unpublished manuscript.

McPherson, M. S., \& Schapiro, M. O. (1991). Does student aid affect college enrollment? New evidence on a persistent controversy. The American Economic Review, 81(1), 309-318.

Page, L. C. \& Scott-Clayton, J. (2016). Improving college access in the United States: Barriers and policy responses. Economics of Education Review, 51, 4-22.

Rizzo, M., \& Ehrenberg, R. G. (2004). Resident and nonresident tuition and enrollment at flagship state universities. In C. M. Hoxby (Ed.), College choices: The economics of where to go, when to go, and how to pay for it (pp. 303-354). Chicago, IL: University of Chicago Press.

Rubin, D. B. (1974). Estimating causal effects of treatments in randomized and nonrandomized studies. Journal of Educational Psychology, 66(5), 688-701.

Schudde, L. (2013). Heterogeneous treatment effects in higher education: Exploring variation in the effects of college experiences on student success (Doctoral dissertation). University of Wisconsin-Madison, WI. 
Scott-Clayton, J. (2013). Information constraints and financial aid policy. In D. E. Heller \& C. Callender (Eds.), Student financing of higher education: A comparative perspective. New York, NY: Routledge Publishing.

Seftor, N. S., \& Turner, S. E. (2002). Back to school: Federal student aid policy and adult college enrollment. Journal of Human Resources, 37(2), 336-352.

Singell, L. D., \& Stone, J. A. (2007). For whom the Pell tolls: The response of university tuition to federal grants-in-aid. Economics of Education Review, 26(3), 285-295.

Turner, L. J. (2014). The road to Pell is paved with good intentions: The economic incidence of federal student grant aid (Working Paper). College Park, MD: University of Maryland. Retrieved from http://econweb.umd.edu/ turner/Turner_FedAidIncidence.pdf

Wiederspan, M. (2016). Denying loan access: The student-level consequences when community colleges opt out of the Stafford Loan Program. Economics of Education Review, 51, 7996. 